University of Louisville

ThinkIR: The University of Louisville's Institutional Repository

\title{
Preventable hospitalization among type 2 diabetes patients in Kentucky before and after medicaid expansion 2010-2017.
}

Turky Jamil Arbaein

University of Louisville

Follow this and additional works at: https://ir.library.louisville.edu/etd

Part of the Health Services Administration Commons, and the Health Services Research Commons

\section{Recommended Citation}

Arbaein, Turky Jamil, "Preventable hospitalization among type 2 diabetes patients in Kentucky before and after medicaid expansion 2010-2017." (2020). Electronic Theses and Dissertations. Paper 3423.

https://doi.org/10.18297/etd/3423

This Doctoral Dissertation is brought to you for free and open access by ThinkIR: The University of Louisville's Institutional Repository. It has been accepted for inclusion in Electronic Theses and Dissertations by an authorized administrator of ThinkIR: The University of Louisville's Institutional Repository. This title appears here courtesy of the author, who has retained all other copyrights. For more information, please contact thinkir@louisville.edu. 


\title{
PREVENTABLE HOSPITALIZATION AMONG TYPE 2 DIABETES PATIENTS IN KENTUCKY BEFORE AND AFTER MEDICAID EXPANSION 2010-2017
}

\author{
By \\ Turky Jamil Arbaein \\ B.S., Umm Al-Qura University (2010) \\ M.S., Clayton State University (2015)
}

\begin{abstract}
A Dissertation
Submitted to the Faculty of the

School of Public Health and Information Sciences of the University of Louisville in Partial Fulfillment of the Requirements for the Degree of
\end{abstract}

Doctor of Philosophy in Public Health Science

Department of Health Management and Systems Sciences

University of Louisville

Louisville, Kentucky

May 2020 
Copyright 2020 by Turky Jamil Arbaein

All rights reserved 



\title{
PREVENTABLE HOSPITALIZATION AMONG TYPE 2 DIABETES PATIENTS IN KENTUCKY BEFORE AND AFTER MEDICAID EXPANSION 2010-2017
}

\author{
By \\ Turky Jamil Arbaein \\ B.S., Umm Al-Qura University (2010) \\ M.S., Clayton State University (2015)
}

A Dissertation Approved on

March 31, 2020

By the following Dissertation Committee:

Dissertation Chair

Bert Little, Ph.D.

Dr. Robert Esterhay, MD

J'Aime Jennings, Ph.D.

Michael Goldsby, Ph.D.

Matthew H. Ruther, Ph.D. 


\section{DEDICATION}

This dissertation is dedicated to my loving parents, Nahla and Jamil who have surrounded me with their eternal love and support ; to my loving wife Rouaa who has encouraged me to pursue my dreams and has been supportive and patient throughout my doctoral studies; and to my wonderful children, Sari, Ziyad, and Sarah.

I thank you all from the bottom of my heart, I love you all. 


\section{ACKNOWLEDGEMENTS}

My sincere gratitude and thanks go to my committee chair and advisor, Dr. Little Bert, for his never-ending patience and wisdom. Thank you for teaching me and guiding me throughout this journey.

I would also like to thank Dr. Robert Esterhay for going above and beyond as committee member in his guidance of this project and for encouraging me to pursue this degree. Also, thank you to Drs. Matt, Goldsby, and Jennings for their continual comments and assistance throughout this project.

Additionally, I would like to thank my family for the never-ending support and encouragement. Specifically, thank you to my wife, Rouaa, for making my life outside of work and school as stress free as possible and being my constant rock. thank you to my mother who gave me the confidence to always push myself to pursue more in life. Also, many thanks to my parents and siblings for their persistence in driving me to reach my goals despite obstacles.

My graduate studies would not have been the same without the social and emotional support of my great friends and colleagues in the School of Public Health and Information Sciences at University of Louisville. Special thanks go to Dr.Sahal, Dr.Mjeed, and Dr.Fatima who gave me the extra encouragement to finish. 


\title{
ASTRACT
}

\section{PREVENTABLE HOSPITALIZATION AMONG TYPE 2 \\ DIABETES PATIENTS IN KENTUCKY BEFORE}

\begin{abstract}
AND AFTER MEDICAID EXPANSION
\end{abstract}
$2010-2017$

Turky Arbaein

$03 / 31 / 2020$

Objectives: 1) Analyze county level variation in T2DM-PH rates in Kentucky before ACA (2010-2013) and after the ACA (2014-2017). 2) Analyze the relationship between county level socioeconomic factors (income per capita, percentage of uninsured people, percent of urban population, primary care and general preventive offices, population aged 65 and above, median age, household income, percentage in poverty, and unemployment rate ) and county level T2DM-PH rates before (2010-2013) and after (2014-2017) ACA implementation in Kentucky.

Method: This research was conducted in two phases: Phase one of this study estimated the county-level PH variation among T2DM patients across eight years (2010-2017), four years (2010-2013) before the Medicaid expansion and the next four years (2014-2017) after the implementation of Medicaid expansion to estimate the ACA impact on health outcomes among T2DM patients in Kentucky. The second phase focused on objective number two, to analyze and compare the socioeconomic factors association with T2DM-PH rates Pre- 
and Post-Medicaid expansion. All county level socioeconomic factors and T2DM-PH rates were extracted from the AHRF data (2010-2017) and merged with Kentucky Hospital Inpatient Discharge Databases (KID) (2010-2017) to estimate and compare the correlations pre- and post-Medicaid expansion.

Results: When the overall T2DM-PH rates Pre- and Post-ACA were assessed, a significant reduction $(8.38 \%)$ in T2DM-PH discharges rates was found in the period of the postexpansion $(\mathrm{P}=0.001)$. However, The spatial statistics analysis revealed significant spatial clustering of counties with similar high rates of T2DM-PH in the southeastern region before and after the expansion. These Counties with cluster type high-high (HH) had high positive z-score, positive Moran's Index values and p-value $<0.05)$ Pre- and Post-ACA. During 2010-2013 and 2014-2017, two PCs Pre-expansion and two PCs Post-expansion accounted for over 75 percent (eigenvalues $>2$ ) of the variation in socioeconomic factors. PC1 loaded with wealth variables, whereas PC2 laded with poverty variables. While counties with high PC1 scores were in the northern region of the State, counties with high PC2 were mainly in the southeastern region Pre- and Post-ACA. The regression coefficients show that there is a positive association between PC2 and county level T2DM$\mathrm{PH}$ rates in Kentucky. The scaled slope (B) indicates the degree to which the T2DM-PH rate changes with a one-unit change in PC2 Pre-ACA $(B=0.972, S E=0313, p=0.002)$ and Post- ACA ( $\mathrm{B}=1.01, \mathrm{SE}=0.218, \mathrm{p}=0.001)$.

Conclusion: The Medicaid expansion was associated with reduced T2DM-PH rates at county level in Kentucky. The Medicaid expansion affected the health coverage, but not the economic expansion. Extremely disadvantaged rural counties in southeast 
Kentucky scored highest on the socioeconomic deprivation profile component (PC2) and was significantly associated with high T2DM-PH rates $(\mathrm{p}<0.05)$. These findings have important public health implications for health policy and economic disparities, calling for ways to enable success of lifestyle intervention programs. Finally, this study identified the need for further investigation into the costs associated with each preventable T2DM hospitalizations to determine the economic impact of Medicaid expansion among T2DMPH in Kentucky. 


\section{TABLE OF CONTENTS}

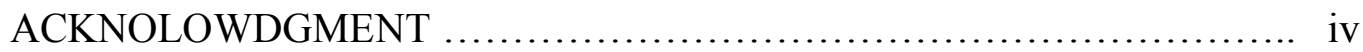

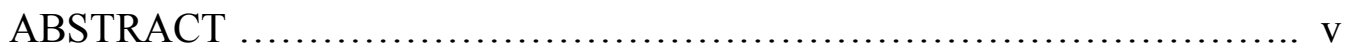

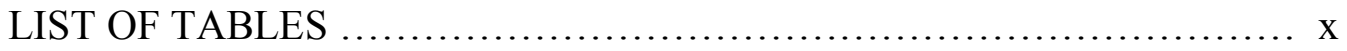

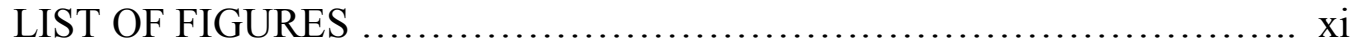

1. CHAPTER I: INTRODUCTION

1.1. Background of the problem................................ 7

1.2. AHRQ measure.............................................. 8

1.3. Economic Burden of T2DM-PH.............................. 10

1.4. Risk Factors inT2DM-PH.................................. 12

1.5. Objectives of the study................................... 13

2. CHAPTER II: REVIEW OF LITERATUR

2.1. Spatial patterns of T2D-PH in Kentucky......................... 15

2.2. Socioeconomic Factors...................................... 20

2.2.1. Social Factors.......................................... 20

2.2.2. Economic Factors....................................... 24

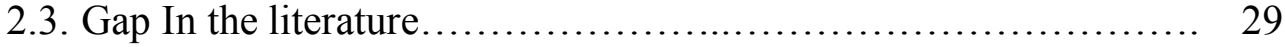

3. CHAPTER III: MATERIAL AND METHODS

3.1. Study design................................................ 30

3.2. Data Source.............................................. 31

3.3. Inclusion and Exclusion Criteria............................... 32

3.4. Study Population.............................................. 34

3.5. Statistical Methods........................................... 35

3.5.1. Descriptive Statistics.................................. 35

3.5.2. Cluster Analysis........................................ 36

3.5.3. Principal Component Analysis.............................. 37

3.5.4. Ordinary Least Squares regression........................... 39

3.5.5. Measured variables.......................................... 40

3.5.6. Data Management......................................... 41

3.5.7. Summary ............................................. 42

\section{CHAPTER IV: RESULTS}

4.1. Descriptive Analysis....................................... 43

4.2. Geographic Mapping for T2DM-PH rates..................... 44

4.3. Cluster Analysis T2D-PH in Kentucky......................... 47 
4.4. Principal Component Analysis .............................. 52

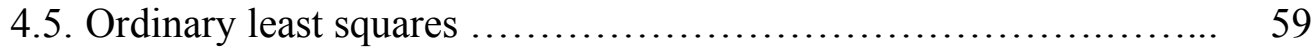

4.6. Summary of Findings......................................... 60

\section{CHAPTER V: DISCUSSION}

5.1. Key Findings................................................ 63

5.2. Variables in T2DM-PH in Kentucky............................. 64

5.3. Association of T2DM-PH with counties Socioeconomic ............ 65

5.4. The economic implication of T2DM-PH in Kentucky................ 70

5.5. Intervention Approach for T2DM-PH in Kentucky.................. 71

5.6. Study Limitation........................................... 75

5.7. Conclusion.................................................... 75

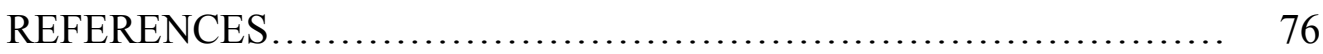

CURRICULUM VITA........................................... 82 


\section{LIST OF TABLES}

Table Page

$1 \quad$ PQI measures of T2DM-PH............................. 10

2 Spatial patterns of T2DM-PH literature review................ 19

3 Literature review for social factors that predict $\mathrm{PH}$ rate......... 23

4 Literature review for association between the lack of health insurance and preventable hospitalizations............................... 27

5 Literature Review for the Association between Poverty and

Preventable Hospitalizations............................. 28

$6 \quad$ Exclusion and Inclusion Criteria.............................. 32

7 The ICD-9 and ICD-10 codes of AHRQ T2DM-PH............ 33

8 County T2DM-PH variations hypothesis...................... 36

$9 \quad$ Cluster analysis output.................................... 37

10 County level T2DM-PH and socioeconomic measures.......... 41

11 Objectives and statistical analyses plan................... 42

12 Descriptive assessment of T2DM-PH ...................... 44

13 Top 20 counties with T2DM-PH rates ..................... 46

14 Cluster analysis Pre-Medicaid expansion...................... 49

15 High-high $(\mathrm{HH})$ cluster analysis Post-Medicaid expansion....... 49

16 Low-low (LL) cluster analysis Pre-Medicaid expansion.......... 50

17 Low-low (LL) cluster analysis Post-Medicaid expansion......... 50 
$18 \quad$ Cluster Analysis Interpretation............................ 51

19 Total variance explained of the PCA Pre-ACA................. 53

20 Total variance explained of the PCA Post-ACA................... 53

21 Structure matrix of the PCA Pre- and Post-ACA................... 54

22 PC1 scores Interpretations Pre- and Post-ACA................... 55

23 Highest 20 PC1 scores across counties .......................... 56

$24 \quad$ PC2 scores Interpretations............................... 57

25 Highest 20 PC2 scores across counties $\ldots \ldots \ldots \ldots \ldots \ldots \ldots \ldots \ldots . . \ldots \ldots$

26 Principal components Predictors of T2DM-PH ................. 60

27 Highlight on the study's results........................... 62 


\section{LIST OF FIGUERS}

Figure page

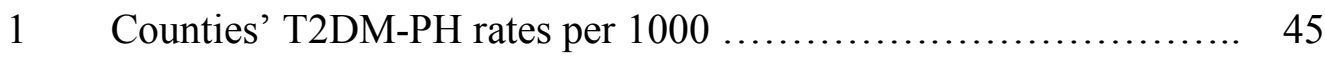

2 Cluster analysis of T2DM-PH ............................. 48

3 Scree plot for the PCA Pre-ACA (a) and Post-ACA (b)........... 53

$4 \quad$ PC1 scores of the counties Pre-ACA (a) Post-ACA (b)............ 56

$5 \quad$ PC2 scores of the counties Pre-ACA (a) Post-ACA (b)............ 59

6 The dispersion of county T2DM-PH rates Pre-ACA (a) and Post-ACA (b) around the regression line $\ldots \ldots \ldots \ldots \ldots \ldots \ldots \ldots \ldots \ldots \ldots \ldots \ldots, 61$

$7 \quad$ Counties by percent living below the poverty level.............. 68

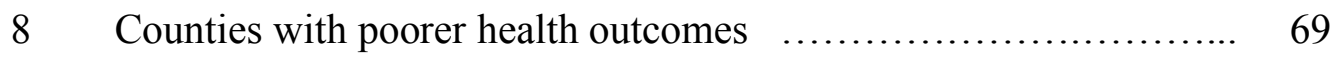

$9 \quad$ Conceptual model of T2DM-PH intervention in Kentucky......... 74 


\section{CHAPTER I INTRODUCTION}

Over the last decade, type-2 diabetes mellitus (T2DM) and its complications are associated with a rapidly growing epidemic in the United States. As of 2018, T2DM affects an estimated 30.3 million people (9.4 percent of the US population) with an estimated total cost (direct and indirect) of $\$ 327$ billion (Riddle \& Herman, 2018). The largest component of medical expenditures is associated with hospital inpatient care (hospitalization) of T2DM patients. It is expected to see T2DM expenditures increase in the future. In 2017, a study forecasts future trends in T2DM prevalence, morbidity, and costs in the United States to increase by 54 percent to more than 54.9 million Americans by 2030. Moreover, the study forecasts the total annual medical and societal costs related to T2DM will increase by 53 percent to more than $\$ 622$ billion by 2030 (Rowley, Bezold, Arikan, Byrne, \& Krohe, 2017).

In Kentucky, diabetes is the sixth leading cause of death (Centers for Disease Control and Prevention, 2016). Kentucky has the seventh highest T2DM rate in the nation (Kentucky Public Health, 2018). From 2000 to 2018, the number of Kentucky adults diagnosed with diabetes has more than doubled from 6.5 percent $(198,052)$ to the current rate of 14.5 percent $(531,646)$ (Kentucky Public Health, 2018). The American Diabetes Association (ADA) estimates that T2DM direct and indirect costs in Kentucky State are an estimated $\$ 4.8$ billion in total medical costs. This indicates that people in Kentucky with 
T2DM had medical expenses approximately 2.3 times higher than those without T2DM (American Diabetes Association, 2017).

In addition to high medical costs, T2DM is also associated with complications that threaten the quality of life. T2DM is the leading cause of adult blindness, end-stage renal disease, neurological complications, and non- traumatic lower-extremity amputations. Poorly controlled T2DM can cause diabetic coma due to hypoglycemia or hyperglycemia, complicate pregnancy resulting in an early delivery and birth defects, preeclampsia (high blood pressure, edema, sudden weight gain, headaches and changes in vision), or intrauterine death (Commonwealth of Kentucky, 2015).

T2DM-associated morbidities and mortalities can be prevented, delayed or significantly reduced through improved patient compliance by working with a support network and health care providers. Delaying or not receiving proper outpatient care for the T2DM complications can result in preventable hospitalizations (Kuo, Chen, Baillargeon, Raji, \& Goodwin, 2015). Preventable hospitalizations (PH) are avoidable hospital admissions and occur when adequate quality care is not accessible to the patient (Van Loenen, Faber, Westert, \& Van den Berg, 2016).

Identification of conditions for which hospitalizations could be prevented is possible. The Agency for Health Research Quality (AHRQ) and the Institute of Medicine (IOM) identify PH as ambulatory care sensitive conditions (ACSCs), which is a measure of access to healthcare (Agency for Healthcare Research and Quality Indicators, 2002). The AHRQ has derived a set of 14 prevention quality indicators (PQIs) to identify PH 
related to T2DM (T2DM-PH), circulatory diseases, chronic respiratory diseases, and some acute conditions (Agency for Healthcare Research and Quality Indicators, 2002).

PQIs are a set of measures that can be used with hospital inpatient discharge data to identify the quality of care and access for ACSC. Proper outpatient care or early outpatient intervention can prevent high costs associated with hospitalization by treating ACSCs in an outpatient setting (Yaqoob et al., 2018). Each PQI is defined by the presence or absence of specific hospital discharge data.

The AHRQ identified T2DM-PH among adults: short-term complications, longterm complications, uncontrolled diabetes, and lower limb amputation (AHRQ Quality Indicators, 2016). Hospitalizations from these conditions could potentially be prevented with improved access to outpatient care. Importantly, high quality care in outpatient settings for diagnosis, treatment, patient education, and active patient follow-up with suitable care (AHRQ Quality Indicators, 2016).

The T2DM-PH can be identified and measured by using PQIs developed by AHRQ. PQI indexes of T2DM admissions are measured per 100,000 population, ages 18 years and older. The T2DM PQI includes admissions for one of the following conditions: T2DM with short-term complications, T2DM with long-term complications, uncontrolled T2DM without complications, and lower-extremity amputations (Table 1) (Agency for Health care Research and Quality, 2018). 
Table 1: PQI measures of T2DM-PH

\begin{tabular}{|l|l|}
\hline \multicolumn{1}{|c|}{ PQI index } & \multicolumn{1}{|c|}{ Definition } \\
\hline $\begin{array}{l}\text { PQI\#1:Short-term } \\
\text { T2DM complications }\end{array}$ & $\begin{array}{l}\text { All admissions of age 18 years and older with ICD-9/ICD-10 primary } \\
\text { diagnosis codes for short-term complications such as ketoacidosis, } \\
\text { hyperosmolarity, or coma. }\end{array}$ \\
\hline $\begin{array}{l}\text { PQI\#3:Long-term } \\
\text { T2DM complications }\end{array}$ & $\begin{array}{l}\text { All admissions age 18 of years and older with ICD-9/ICD-10 primary } \\
\text { diagnosis codes for long-term complications such as retinopathy, blindness, } \\
\text { macular edema, gangrene, skin ulcer, or end-stage kidney disease. }\end{array}$ \\
\hline $\begin{array}{l}\text { PQI\#14: Uncontrolled } \\
\text { T2DM }\end{array}$ & $\begin{array}{l}\text { All admissions of age 18 years and older with ICD-9/ICD-10 primary } \\
\text { diagnosis code for uncontrolled T2DM, without mention of a short-term or } \\
\text { long-term complications such as hyperglycemia, hypoglycemia, or birth } \\
\text { defect. }\end{array}$ \\
\hline $\begin{array}{l}\text { PQI\#16:Lower- } \\
\text { extremity } \\
\text { amputations }\end{array}$ & $\begin{array}{l}\text { All admissions for patients ages 18 years and older with any-listed ICD- } \\
\text { 9/ICD-10 diagnosis code for T2DM and any-listed ICD-9/ICD-10 procedure } \\
\text { codes for lower-extremity amputation such as lower limb amputation, } \\
\text { disarticulation of knee, foot amputation, or above knee amputation. }\end{array}$ \\
\hline
\end{tabular}

Hospitalizations are more resource intensive and expensive than outpatient care, therefore T2DM-PH can be seen as a major topic of research efficiency in the healthcare system. A major objective of national and state healthcare policies in the United States is to improve access to outpatient care health services (Kentucky Department for Public Health, 2017). The Medicaid expansion and health insurance exchange provisions of the Patient Protection and Affordable Care Act of 2010 (ACA) are recent national policies enacted to broaden access through expanding insurance coverage for vulnerable populations nationwide (French, Homer, Gumus, \& Hickling, 2016). In Kentucky, Governor Beshear announced an executive order in 2014 to enact Medicaid expansion. Medicaid coverage was expanded to include all individuals and families with incomes up to 138 percent of the federal poverty level (FPL) (Kentucky Cabinet for Health and Family Services, 2017). Approximately, 413,000 Kentuckians enrolled in expanded Medicaid or a qualified health plan offered on the healthcare exchange following expansion. The Medicaid expansion means that more Kentuckians with T2DM are eligible to receive 
access to vital health care to improve their quality of life and T2DM outcomes in the state. The State successfully reduced the number of uninsured Kentuckians from 25 percent in 2013 to 11 percent in 2017 (Kentucky Cabinet for Health and Family Services, 2017).

Advocates of Medicaid expansion argue that it can drive down the uninsured rate. However, the question remains, does a lower uninsured rate translate into better health outcomes? Each year, America's Health Rankings issues a health ranking of the 50 states. In the most recent year available, Kentucky was ranked $50^{\text {th }}$, highlighting the worst $\mathrm{PH}$ rate in the country (America's Health Rankings, 2018).

Poor access to quality outpatient care is an important risk factor for T2DM-PH. It has become increasingly clear that other factors such as geographical and socioeconomic factors are important determinants of access (Pezzin et al., 2018). Detailed geographic analyses of several patterns of illness underpinned major public health interventions, accounting in large part for the control of communicable diseases in developed countries (Stevens et al., 2014). Researchers began to explore similar strategies to reduce the impact of access on chronic diseases. The emergence of geographic information systems (GIS) and publicly available databases created new methods to better understand causes and target interventions for chronic illness such as T2DM using geographic pattern analysis (Stevens et al., 2014). Spatial patterns of PH can identify low utilization, high demand for health services, and poor socioeconomic circumstances of regions (Nkem, 2014; Yaqoob et al., 2018) because $\mathrm{PH}$ rates are indicators of regional healthcare market activity and health services utilization (Nkem, 2014). 
Socioeconomic characteristics include factors such as income, employment, demographics, and social support systems that may significantly affect people's quality of life (Veru-Lesmes, Rho, Joober, Iyer, \& Malla, 2019). These factors affect one's ability to make healthy choices, opening the door for negative health outcomes (Veru-Lesmes et al., 2019). For example, employment provides the income that shapes choices regarding housing, education, childcare, food, medical care, and more. In contrast, unemployment limits these choices and the ability to accumulate savings and assets that can be a cushion in times of economic distress (Cho et al., 2019).

Past studies found that socioeconomic disparities are related to the incidence and prevalence of T2DM. These studies found that individuals with a low income, lower education, who were unemployed, as well as those living in disadvantaged areas face a higher probability of having T2DM (Degerlund Maldi, San Sebastian, Gustafsson, \& Jonsson, 2019). Additionally, researchers found that socioeconomic disparities were related to various aspects of T2DM care, such as the method of treatment, the quality of care, and health outcomes such as mortality and morbidity (P. C. Chen, C. Y. Tsai, L. C. Woung, \& Y. C. Lee, 2015). Previous studies indicate that individuals with higher socioeconomic status are more likely to be tested or treated for T2DM, more likely to experience normal glucose levels, and had a lower probability of T2DM-related morbidities and mortality (P. C. Chen et al., 2015). 
However, a limited number of studies have explored the relationship between socioeconomic disparities and $\mathrm{PH}$, and they reported an inverse proportional relationship between income level and PH rates (Stockbridge, Chhetri, Polcar, Loethen, \& Carney, 2019). Previous researchers also found that living in rural areas or low-income neighborhoods was also associated with PH (P. C. Chen et al., 2015). However, very limited research is available on T2DM patients at the regional level related to socioeconomic status and T2DM-PH. The approach of the present study is the use of a robust county-level dataset and the application of a unique analytical methodology that accounts for ecological factors. Understanding the determinants of the T2DM-PH can help improve the county level health quality, efficiency, and equity of health care delivery.

The overall goal of this study is to analyze and compare T2DM-PH rates before and after the ACA in Kentucky. Specific objectives to achieve this goal are:

\section{Objective 1:}

Analyze county level variation in T2DM-PH rates in Kentucky before ACA (2010-2013) and after the ACA (2014-2017).

\section{Objective 2:}

Analyze the relationship between county level socioeconomic factors (income per capita, percentage of uninsured people, percent of urban population, primary care and general preventive offices, population aged 65 and above, median age, household income, percentage in poverty, and unemployment rate ) and county level T2DM-PH rates before (2010-2013) and after (2014-2017) ACA implementation in Kentucky. 
The ACA expanded access to health insurance for hundreds of thousands of Kentuckians, but the impact of Medicaid expansion on PH among T2DM patients has not been analyzed. The outcome of the present study will offer a better understanding for policymakers of the socioeconomic and geographical impact of the Medicaid expansion on T2DM-PH. This study's results will also provide policymaking evidence for the analysis of the comparative efficacy of policies for improving access to healthcare among T2DM patients, and reducing costs associated with T2DM-PH events. In this dissertation, geography and socioeconomic factors were analyzed with the objective of predicting county level T2DM-PH rates before and after ACA implementation in Kentucky. 


\section{CHAPTER II \\ LITERATURE REVIEW}

\section{Spatial Patterns of T2DM-PH in KY:}

The ACA healthcare reform is directed at the triple aim of better access to care, better quality of care, and lower costs (Mahal et al., 2019). However, questions remain about how the ACA is affected by the significant geographic variation in healthcare spending and utilization. Researchers recognize the importance of geography, and have developed a cluster analysis approach for targeting high need communities (Tampah-Naah, Osman, \& Kumi-Kyereme, 2019). This approach offers models to identify priority regions that policymakers can use to improve the overall healthcare outcomes on targeted geographic level populations.

A large body of work highlights disparities in access to coordinated preventive care in patients with T2DM and other chronic diseases. A limited number of studies have analyzed geographic patterns of major preventable complications of chronic diseases such as T2DM in the US. No studies are published on comparative analysis of the geospatial patterns of PH among T2DM patients before and after Medicaid expansion in the US, or Kentucky.

The published literature indicates that spatial variation in PH occurs at the national level, hospital referral region, county, as well as primary care service area level. Depending on the geographic level analyzed and the condition or treatment studied, the magnitude of 
geographic differences in health services utilization differ widely. County level T2DM-PH spatial patterns are the geographic distribution preventable T2DM hospitalizations rates relative to other counties' preventable T2DM hospitalizations rates. Spatial patterns of preventable T2DM hospitalization rates illustrate low utilization and high demand for health services. The high hospitalization rate for T2DM is the result of limited access to healthcare because of the low supply of health coverage, deficiency in outpatient infrastructure, or lack of patient adherence and compliance (Stevens et al., 2014). These effects are likely greatest among populations facing financial and geographic barriers to care (Stevens et al., 2014).

Wen et al. (2019) conducted a national study to examine all-payer PH to determine the extent to which Medicaid expansion affected $\mathrm{PH}$ of ambulatory care sensitive conditions. The study used the Healthcare Cost And Utilization Project (HCUP) state inpatient databases. The study's main analyses used inpatient discharge data from thirtysix states that participated in the HCUP databases in the period 2009-2013 (before Medicaid expansion) and 2014-2015 (after Medicaid expansion) (Wen, Johnston, Allen, \& Waters, 2019). The study used a quasi-experimental difference-in-differences approach in analyzing relative changes at the State level from the pre-expansion period of 2009-13 to the post-expansion period of 2014-15. A significant reduction was estimated in state level ACSC discharge rates (11.96 percent v. 7.80 percent) was found (Wen et al., 2019). Reduction in PH associated with Medicaid expansion was found to be largely concentrated in chronic respiratory conditions (COPD, asthma), diabetes-related complications, and bacterial pneumonia (Wen et al., 2019). 
Mondesir et al (2019) conducted a retrospective state level analysis of 2013-2014 hospital discharge data for adults with T2DM. The study compared PH rates in the states that expanded and with those that did not expand Medicaid by using the HCUP database (Mondesir et al., 2019). The study found that from 2013 (Pre-Medicaid expansion) and 2014 (Post-Medicaid expansion) Medicaid expansion was associated with decreases in proportions of PH for adults with T2DM (difference between 2014 and 2013 was 17 percentage points in expansion States and 37 percentage points in non-expansion States, $p$ $=0.04)$ (Mondesir et al., 2019). The investigation concluded that increased access to care through Medicaid expansion may improve disease management in non-elderly adults with diabetes (Mondesir et al., 2019).

The study was conducted at a very high level, masking within state variation. For instance, with Kentucky's mainly white population, household income, and other unique socioeconomic characteristics in each county, the simplification of nationwide PH spatial variation will not detect inter-county variation in Kentucky.

A state level study conducted by Margolis et al. showed variation clusters of neighboring hospital referral regions with high $\mathrm{PH}$ rates of ACSC were most common among elderly in southeastern U.S. States: Texas, Oklahoma, Louisiana, Arkansas, and Mississippi (Margolis et al., 2011). The study focused on the nationwide PH geographic variation's contributing factors, with limited attention to county level $\mathrm{PH}$ variation in the five States.

Helmer et al. (2018), conducted a national retrospective study of the association between reliance on the Veterans Health Administration (VHA) ambulatory care and total PH rates at the state level to better inform local and regional healthcare planning. The study 
used VHA data on T2DM mellitus patients, aged 66 years or older, and dually enrolled in VHA and Medicare parts A and B from 2004 to 2010 (Helmer et al., 2018). The study evaluated geospatial patterns in PH rates using global Moran's I and univariate local indicator spatial analysis. The study found that approximately 30 percent of hospitalized veterans experienced a PH (Helmer et al., 2018). While there was low reliance on VHA ambulatory care and lack of association with $\mathrm{PH}$ rates, geospatial analysis in the study identified a consistent cluster of the Mideast states including Kentucky with high PH rates (Helmer et al., 2018). Although the study had a focus on veterans at the States level, it showed the magnitude of the PH problem among diabetic patients in Kentucky.

Malachy Nkem (2014) conducted a study focused on the variation of county-level $\mathrm{PH}$ rates in Texas. The study showed spatial clustering of counties with similar rates of $\mathrm{PH}$ in the northeastern and southern regions of the state, indicating that counties with similar PH rates are not randomly dispersed (Nkem, 2014).

Mobley et al. conducted a spatial analysis of nationwide elderly access in the 1990s to primary care services in 2006 . The study used the local Moran test to identify spatial clusters of the relationship between market-level supply and demand factors on the PH of Medicare beneficiaries in the 1990s. However, the primary care service area during the 1990s was created with Medicare utilization data that include the geographical healthcareseeking behavior of the elderly population (Mobley, Root, Anselin, Lozano-Gracia, \& Koschinsky, 2006). Therefore, Mobley's findings on spatial patterns are not generalizable to the nationwide non-elderly population. The spatial pattern of $\mathrm{PH}$ among populations in the nation was not reported in the study results. 
A limited number of studies used the local Moran index statistic which is based on ordinary least square regression (OLS) estimation of autocorrelation among features surrounding each other, along with z-score and p-value to identify significant spatial clusters (Table 2).

Table 2: Spatial Patterns of T2DM-PH Literature Review

\begin{tabular}{|c|c|c|c|}
\hline Area & Author & Study Design and Analyses & Key Findings \\
\hline \multirow{3}{*}{$\begin{array}{l}\text { Spatial Patterns of } \\
\text { Preventable } \\
\text { Hospitalization }\end{array}$} & $\begin{array}{l}\text { Margolis et al., } \\
2011\end{array}$ & $\begin{array}{l}\text { Moran's Index test was utilized } \\
\text { in a cohort nationwide study to } \\
\text { identify geographic clustering of } \\
\text { hospitalizations rates related to } \\
\text { PQl\#16 lower-extremity } \\
\text { amputation among diabetic } \\
\text { patients during 2006, 2007, and } \\
2008 \text { U.S. Medicare beneficiary } \\
\text { information from hospital } \\
\text { referral regions. }\end{array}$ & $\begin{array}{l}\text { The study found statistically } \\
\text { significant Moran's Index ( } p< \\
\text { O.00001) for clustering of } \\
\text { preventable lower-extremity } \\
\text { amputation hospitalizations rates } \\
\text { in the southeastern Texas, } \\
\text { Southern Oklahoma, Louisiana, } \\
\text { Arkansas, and Mississippi, and low } \\
\text { preventable lower-extremity } \\
\text { amputation hospitalizations rates } \\
\text { ( } p<0.001 \text { ) in South Florida, New } \\
\text { Mexico, Arizona, and eastern } \\
\text { Michigan. }\end{array}$ \\
\hline & $\begin{array}{l}\text { Malachy Nkem } \\
2014\end{array}$ & \begin{tabular}{|l|} 
Moran's Index was utilized to \\
conduct a cluster analysis \\
analysis of PH variations among \\
non-elderly across counties in \\
Texas.
\end{tabular} & $\begin{array}{l}\text { The study indicated statistically } \\
\text { significant spatial clustering of } \\
\text { highly PH rate in the counties with } \\
\text { similar rates of PH were found in } \\
\text { the northeastern and southern } \\
\text { regions of the state. }\end{array}$ \\
\hline & Mobley et al. 2006 & $\begin{array}{l}\text { Local Moran's test was utilized } \\
\text { to conduct a nationwide spatial } \\
\text { patterns study of preventable } \\
\text { hospitalizations among the } \\
\text { elderly population in the } \\
\text { primary care service area across } \\
\text { the country using Medicare } \\
\text { claims files data. }\end{array}$ & $\begin{array}{l}\text { The study found clusters of } \\
\text { primary care service areas with } \\
\text { high rates of preventable } \\
\text { hospitalization in the southern and } \\
\text { eastern states. However, it did } \\
\text { indicate if these spatial clusters } \\
\text { were significant. }\end{array}$ \\
\hline
\end{tabular}

\section{Socioeconomic Factors}


Studies confirm that poor access to primary care is an important risk factor for T2DM-PH. However, it has become increasingly clear that other social and economic factors are also important. Socioeconomic status, whether assessed by income, demographics, or occupation, is linked to a wide range of negative health outcomes, including PH. Lower socioeconomic status is associated with a higher probability of negative health outcomes (Feng et al., 2018). For example, a recent study found that Canadians residing in low-income communities were 40 percent more likely to have $\mathrm{PH}$ than were their counterparts residing in high-income communities (Feng et al., 2018). Another study reported that high rates of PH for ACSCs were significantly associated with socio-demographic profiles such as age, primary care physician (PCP), and rural residence (Rizza, Bianco, Pavia, \& Angelillo, 2007). The elderly, poor, living in rural communities with limited access to PCP had the higher PH rates (Rizza et al., 2007).

\section{Social factors}

A number of Kentucky health access studies identified social characteristics as significant contributing factors for rates of $\mathrm{PH}$ among adults with T2DM. These factors are established in the literature, as common predictors of multiple PH related to ACSCs, including T2DM. The social factors are predisposing characteristics that influence access to care and, therefore, influence the rates of T2DM-PH among adults as it is shown in (Table 3).

The published literature indicates advanced age increases the rates of $\mathrm{PH}$ for ACSCs. According to Kim et al. (2011), the elderly (65 years and older) age group with T2DM is more susceptible to acute or chronic $\mathrm{PH}$ than younger age groups in California 
(H. Kim, Helmer, Zhao, \& Boockvar, 2011). Also, Daly et al., investigated the association between older adults' PH rates in a geographic measure of PCP access and a standard bounded-area measure of PCP access in Virginia (Daly, Mellor, \& Millones, 2018). They merged patient-level hospital discharge data from Virginia Health Information systems with the Area Health Resources Files. Spatial regression techniques and ArcGIS were used to model PH rates and calculate geographic accessibility (Daly et al., 2018). They found that increased access to PCPs was associated with lower rates of PH for ACSCs among older adults (Daly et al., 2018).

On the other hand, Falster et al. (2015) quantified the relative contributions of the PCP supply and personal sociodemographic and health characteristics, to geographic variation in PH rates (Falster et al., 2015). Multilevel Poisson regression models with participants clustered in their geographic area of residence were used to explore factors that explain geographic variation in PH rates. The study found that PCP supply was not a significant predictor of $\mathrm{PH}$ and explained only a small amount (2.9 percent) of the geographic variation in PH rates for ACSCs (Falster et al., 2015). Conversely, more than one-third (36.9 percent) of variation was driven by the sociodemographic composition, health, and behaviors of the population. These personal characteristics explained a greater amount of the variation for chronic conditions (37.5 percent) than acute (15.5 percent) or vaccine-preventable conditions (2.4 percent) (Falster et al., 2015).

Lower-extremity amputation, a preventable complication of T2DM, was investigated by Minc et al. (2019) in Virginia. The objective of the study was to identify patients admitted with T2DM in a rural area to identify the geographic areas with higher than expected major and minor amputations using advanced spatial analysis, controlling 
for comorbidities and rurality (Minc et al., 2019). The study used the Virginia State inpatient database from 2011 to 2016. Geographic analysis found significant variation in risk for amputation across the state (Minc et al., 2019). Also, it indicated an increased risk of amputation hospitalization in western regions of Virginia where 97 percent of the population is rural (low level of urbanization) and poor (Minc et al., 2019).

In addition, Johnston et al. analyzed factors that account for disparities in health outcomes among rural-urban Medicare beneficiaries in a nationally representative survey of Medicare beneficiaries with one or more complex chronic conditions, including T2DM (Johnston, Wen, \& Joynt Maddox, 2019). The sample represented 61 percent of rural and 57 percent of urban Medicare beneficiaries. Investigations found that rural residence was associated with a 40 percent higher $\mathrm{PH}$ rate and a 23 percent higher mortality rate, compared to urban residence (Johnston et al., 2019). Also, the study indicated that access to specialists accounted for 55 percent and 40 percent of the rural-urban disparities in $\mathrm{PH}$ rates and mortality, respectively (Johnston et al., 2019).

Table 3: Literature review for social factors that predict $\mathrm{PH}$ rate 


\begin{tabular}{|c|c|c|c|c|}
\hline & Section & First Author & Study Design and Analyses & Key Findings \\
\hline \multirow{4}{*}{$\begin{array}{l}\text { Social } \\
\text { Factors }\end{array}$} & Age & $\begin{array}{l}\text { Kim et al. } \\
(2011)\end{array}$ & $\begin{array}{l}\text { Prevalence of PH related to diabetes } \\
\text { conditions were examined to } \\
\text { determine the associations of } \\
\text { sociodemographic and health-related } \\
\text { factors as well as hospitalization } \\
\text { history with PH. California State } \\
\text { Inpatient Databases, } 2005 \text { to } 2006 \\
\text { were utilized for the analysis }\end{array}$ & $\begin{array}{l}\text { The study found that individuals } \\
65 \text { years and older represent } \\
\text { one-fifth of total hospitalizations } \\
\text { in California during } 2005 \text { and } \\
2006 \text { of adults } 65 \text { years and } \\
\text { older with diabetes were PH. }\end{array}$ \\
\hline & \multirow[b]{2}{*}{$\begin{array}{l}\text { Rural/Urban } \\
\text { Residence }\end{array}$} & $\begin{array}{l}\text { Daly et al. } \\
\text { (2018) }\end{array}$ & $\begin{array}{l}\text { Investigated the association between } \\
\text { older adults' PH rates and both a } \\
\text { geographic measure of PCP access and } \\
\text { a standard bounded-area measure of } \\
\text { PCP access in Virginia state. }\end{array}$ & $\begin{array}{l}\text { The study found that increased } \\
\text { geographic access to PCPs is } \\
\text { associated with lower rates of } \\
\text { PH for ACSCs among older } \\
\text { adults }\end{array}$ \\
\hline & & $\begin{array}{l}\text { Falster et al. } \\
(2015)\end{array}$ & $\begin{array}{l}\text { Quantified the relative contributions of } \\
\text { the supply of PCP and personal } \\
\text { sociodemographic and health } \\
\text { characteristics, to geographic variation } \\
\text { in PH rates. Multilevel Poisson models } \\
\text { with participants clustered in their } \\
\text { geographic area of residence were } \\
\text { used to explore factors that explain } \\
\text { geographic variation in PH rates. }\end{array}$ & $\begin{array}{l}\text { The study found that PCP was } \\
\text { not a significant predictor of } \mathrm{PH} \\
\text { and explained only a small } \\
\text { amount }(2.9 \%) \text { of the } \\
\text { geographic variation in PH rates } \\
\text { for ACSCs. }\end{array}$ \\
\hline & РCP & $\begin{array}{l}\text { Johnston et } \\
\text { al. (2019) }\end{array}$ & $\begin{array}{l}\text { Conducted a study to understand what } \\
\text { are the factors that account for } \\
\text { disparities in health outcomes among } \\
\text { rural-urban Medicare beneficiaries. } \\
\text { They examined a nationally } \\
\text { representative survey of Medicare } \\
\text { beneficiaries with one or more } \\
\text { complex chronic conditions including } \\
\text { diabetes }\end{array}$ & $\begin{array}{l}\text { The study found that rural } \\
\text { residence was associated with a } \\
40 \text { percent higher PH rate and a } \\
23 \text { percent higher mortality rate, } \\
\text { compared to urban residence. }\end{array}$ \\
\hline
\end{tabular}

\section{Economic factors}


A number studies indicate that the level of income inequality (e.g. variation in median household income) among households within a geographic area, in addition to family-level income, are associated with poorer health outcomes (J. Kim, Kang, Lee, Min, \& Shin, 2019). Low income can be a barrier to health services, in particular for ACSCs, because their treatment depends on access to appropriate health care (J. Kim et al., 2019). Most previous studies that examined economic disparities and the incidence or prevalence of diabetes found that individuals with a low income and those living in disadvantaged areas (e.g. rural) face a higher probability of developing T2DM (P.-C. Chen, C.-Y. Tsai, L.-C. Woung, \& Y.-C. J. I. j. f. e. i. h. Lee, 2015). Few studies have analyzed the relationship between income disparities and $\mathrm{PH}$ rates and found a disproportional relationship between income level and PH rates (P.-C. Chen et al., 2015). Indeed, previous researchers reported that living in rural areas or low-income neighborhoods was associated with PH (Falster et al., 2015). However, few researchers focused on T2DM patients in the analyses, and data related to economic status and T2DM-PH that was particularly lacking at the county levels. In the present study, the economic characteristics are based on county level income factors such as household income, percentage in poverty, income per capita, percentage of uninsured people, and unemployment rate. These are enabling characteristics that influence access to care and, therefore, influence T2DM-PH rates among adults.

A study published in 2016 assessed whether PH rates decreased in low-income neighborhoods from 2008 to 2013 (before the Medicaid expansion) and whether the gap between very high and low-income neighborhoods changed over time (Bocour \& Tria, 2016). PH rates were calculated for each neighborhood income level and applied to inpatient hospitalization data from the New York State Department of Health's Statewide 
Planning and Research Cooperative System (Bocour \& Tria, 2016). The study found that from 2008 to 2013, PH rates per 100,000 adults across each income group decreased. For low income neighborhoods, significant decreases occurred overall (Bocour \& Tria, 2016). However, the T2DM-PH rates for low-income neighborhoods were two to four times higher than in higher-income neighborhoods. The study concluded that while $\mathrm{PH}$ rates had decreased over time, disparities still exist (Bocour \& Tria, 2016).

Bettenhausen et al. (2017) conducted a retrospective cross-sectional analysis after the Medicaid expansion. They used the 2014 HCUP databases from 14 states to determine the influence of income inequality on PH rates for ACSCs (Bettenhausen et al., 2017). The study defined income inequality by median household income and total population for each zip code in 14 States. Zip codes were then divided into quartiles for low, low-middle, highmiddle, and high-income inequality (Bettenhausen et al., 2017). After adjustment for median household income and state of residence, the study found PH rates for ACSCs per 10,000 increased significantly as income inequality increased from low $(27.2 ; 95 \% \mathrm{CI}$, 26.5-27.9) to low-middle (27.9; 95\% CI, 27.4-28.5), high-middle (29.2; 95\% CI, 28.629.7), and high (31.8; 95\% CI, 31.2-32.3) categories $(\mathrm{P}<0.001)$ (Bettenhausen et al., 2017).

Health insurance is a decisive element in access to healthcare in Kentucky. It is an essential determinant of preventive care utilization. Patients without health insurance are deterred from seeking care in primary healthcare centers because of their inability to pay for services (Taber, Leyva, \& Persoskie, 2015). Health insurance coverage encourages patients to access healthcare services (Adepoju, Preston, \& Gonzales, 2015). A sizable proportion of adults had a higher likelihood of $\mathrm{PH}$ because they lack health insurance 
coverage for primary care. The rate of uninsured adults is a serious public health problem because people without health insurance receive healthcare largely through the emergency departments or indigent healthcare clinics (Rust et al., 2009). A large proportion of uninsured patients in emergency departments limit these facilities' capacity to respond to true emergencies. Additionally, it strains the operations and finances of healthcare care providers (Rust et al., 2009).

Uninsured individuals are more susceptible to PH for any ACSC like congestive heart failure, T2DM, heart attacks, and acute conditions (Fisher \& Ma, 2015). The percentage of uninsured Kentuckians has dramatically decreased since Kentucky implemented the Affordable Care Act and expanded Medicaid coverage under the law to those making up to 138 percent of the FPL (L. A. Blewett, C. Planalp, \& G. J. A. j. o. p. h. Alarcon, 2018). The rate of uninsured individuals in Kentucky has declined from 15.3 percent in 2010 to 5.4 percent in 2017 (Lynn A Blewett et al., 2018). Although Kentucky outpaced most of the other states in reducing its uninsured population, the rate of $\mathrm{PH}$ in Kentucky is the highest in the nation, according to America's Health Rankings (America's Health Rankings, 2018).

According to the literature, a few studies explored the relationship between health insurance coverage and rates of T2DM-PH. It is not clear whether self-paying patients (uninsured) had higher susceptibility to PH than insured patients. Table 3 summarizes the studies that analyzed the association between the lack of health insurance and $\mathrm{PH}$ for ACSCs. Most studies reported a positive association between lack of health insurance and $\mathrm{PH}$ in general. However, there is lack of research exploring the association between selfpay and rates of PH related to T2DM in Kentucky during 2010-2017. 
Table 3: Literature Review for Association between the Lack of Health Insurance and Preventable Hospitalizations

\begin{tabular}{|c|c|c|c|c|}
\hline & Section & First Author & Study Design and Analyses & Key Findings \\
\hline \multirow[t]{2}{*}{ Enabling } & \multirow[t]{2}{*}{ Uninsured } & $\begin{array}{l}\text { Malachy } \\
\text { Nkem (2014) }\end{array}$ & $\begin{array}{l}\text { A cross-sectional study } \\
\text { design and a county-level } \\
\text { PH rate spatial regression } \\
\text { were used to evaluate non- } \\
\text { elderly adult } 2011 \text { Texas } \\
\text { Health Care Information } \\
\text { Collection hospital } \\
\text { discharges. }\end{array}$ & $\begin{array}{l}\text { The study results show insignificant relationship } \\
\text { between uninsured and rates of PH at the county } \\
\text { level in Texas. That may because Texas has } \\
\text { indigent health that provides access to inpatient } \\
\text { care for most counties' uninsured. }\end{array}$ \\
\hline & & $\begin{array}{l}\text { Murty et al. } \\
(2011)\end{array}$ & $\begin{array}{l}\text { A cross-sectional study } \\
\text { design and a logistic } \\
\text { regression were used to } \\
\text { evaluate non-elderly adult } \\
2008 \text { hospital discharges. }\end{array}$ & $\begin{array}{l}\text { The study found that uninsured non-elderly adults } \\
\text { had a } 24 \% \text { higher susceptibility of preventable } \\
\text { hospitalizations. Also, study mentioned that the } \\
\text { uninsured total costs of PH were } 3.5 \% \text { lower than } \\
\text { for the insured. }\end{array}$ \\
\hline
\end{tabular}

\section{Poverty}

Poverty has long been recognized as a significant contributor to disease burden.

Several studies reported the impact of poverty and income on access to healthcare. Compelling evidence reveals that people in poverty and lacking health insurance have low access to care. Compared to higher-income people, the poor are more likely to face greater barriers to medical care access and maintaining health insurance. Poor populations are also more likely to be hired by employers who do not provide health insurance (Batavia, Beaulaurier, \& Welfare, 2001). After the implementation of the ACA, more than twentyseven million Americans remain uninsured, the majority of whom are low-income individuals (Foundation, 2016). The US uses FPL to index the minimum income required to provide basic necessities (e.g. food, clothing, shelter and transportation) (Sraders, 2018). Also, FPL is used by state governments to determine the eligibility for public insurance such as Medicaid or Children's Health Insurance Program (CHIP). Therefore, the poverty level is very influential in predicting access to healthcare. 
In Kentucky, 34 percent of the population is below 200 percent FPL (State Health Facts, 2017). The rates of poverty differ from county to county. For instance, the poverty rate in Wolfe county is 42.2 percent, whereas in Oldham county the poverty rate is only 6 percent (State Health Facts, 2017). Low-income individuals who lack access to healthcare had a higher likelihood of PH compared with higher income people (Hakeem, Howard, Carey, Taylor, \& Practice, 2009). The literature uniformly reports a positive association between poverty and PH (Table 6).

Table 6: Literature Review for the Association between Poverty and Preventable Hospitalizations 


\begin{tabular}{|c|c|c|c|}
\hline Section & First Author & Study Design and Analyses & Key Findings \\
\hline & $\begin{array}{l}\text { Hakeem et al. } \\
(2009)\end{array}$ & $\begin{array}{l}\text { The study examined the differential } \\
\text { effects of race and poverty on PH } \\
\text { utilizing Centers for Medicare and } \\
\text { Medicaid Services Denominator } \\
\text { files and } 2000 \text { U.S. Census data. } \\
\text { Descriptive statistics and a Poisson } \\
\text { regression were used for multiple- } \\
\text { variate analyses of the dataset. }\end{array}$ & $\begin{array}{l}\text { The study showed race differentials in } \\
\text { hospitalizations for all ambulatory care sensitive } \\
\text { conditions including diabetes in low- poverty } \\
\text { areas. For unadjusted } \mathrm{PH} \text {, the rate ratio for African } \\
\text { Americans was high in high-poverty areas } \\
\text { compared to low-poverty areas. }\end{array}$ \\
\hline Poverty & $\begin{array}{l}\text { Chen et al. } \\
(2015)\end{array}$ & $\begin{array}{l}\text { This study examined the connection } \\
\text { between diabetes-related } \\
\text { preventable hospitalization and the } \\
\text { individual level of income among } \\
\text { all diabetes patients aged } 18 \text { and } \\
\text { older who received regular care in } \\
2010 \text { in Taiwan. The study utilized } \\
\text { Longitudinal Health Insurance } \\
\text { Database } 2010 \text {, which provided a } \\
\text { representative cohort comprising } \\
\text { one million people enrolled in } \\
\text { Taiwan's National Health Insurance } \\
\text { in } 2010 \text {. }\end{array}$ & $\begin{array}{l}\text { A total of } 57,791 \text { patients from } 25 \text { regions in } \\
\text { Taiwan diagnosed with T2DM mellitus identified } \\
\text { in the National Health Insurance claim data for the } \\
\text { year } 2010 \text {. After controlling for the characteristics } \\
\text { of patients and health care providers, the study } \\
\text { found that dependents and patients in low income } \\
\text { as well as those living in regions with a low } \\
\text { education face a higher probability of preventable } \\
\text { hospitalization. }\end{array}$ \\
\hline
\end{tabular}

\section{Gaps in the Literature}

Some studies have investigated healthcare access disparities in Kentucky, but no published study thus far has analyzed the comparative rate of PH among T2DM adults before and after the Medicaid expansion. In addition, no published study has investigated variation of T2DM-PH using the Moran's Index tool to analyze clusters during the two periods of time (2010-2013) and (2014-2017) across the counties. Moreover, the current investigation will fill a gap in the literature by analyzing the comparative importance of socioeconomic factors on the county-level rate of $\mathrm{PH}$ among T2DM adults before and after the Medicaid expansion. This dissertation analyzes geographic autocorrelation using principal components analysis and linear regression. The results can add valuable 
information to current literature and be made available to policymakers in Kentucky, which can be used to improve healthcare access.

The present investigation analyzes and compares T2DM-PH before the Medicaid expansion 2010-2013 and after the Medicaid expansion 2014-2017. It is hypothesized that the Medicaid expansion will be associated with lower proportions of PH among T2DM adults in Kentucky. A positive relationship between socioeconomic factors and T2DM-PH on the county level is assumed during the two compared timeframes. 


\section{CHAPTER III \\ MATERIALS AND METHODS}

The advantage of the present study is the use of a large county-level data set and the application of an advanced analytical methodology that includes ecological factors. Compared to published studies that used national data sets (i.e., Utilization Project Nationwide Inpatient Sample data, Medicare beneficiary files) that are outdated or focused only on the Medicare population, this study used the Kentucky Inpatient Dataset (KID) which is the most recent available at the county-level for hospital discharge. KID includes a collection of records describing each inpatient stay in Kentucky. Unlike the HCUP, which utilizes a sample of discharges from a few hospitals and sets strict reporting and data compatibility checks for States, the KID includes data from every stay at all hospitals in Kentucky. The data are reviewed by the Kentucky Cabinet for Health and Family Services, Office of Health Data and Analytics to verify and conform at the hospital and state levels.

\section{Study Design:}

This study aims to predict T2DM-PH rates before and after Medicaid expansion in Kentucky using geographic and socioeconomic factors on the county level. All data used were derived from county-level data on hospital discharges from KID 2010-2017 and the Area Health Resources Files (AHRF) 2010-2017 (HRSA, 2018). This research was conducted in two phases: first, analyzing of the county level T2DM-PH variation, and second, analysis of its association with county level socioeconomic factors. 
Phase one of this study estimated the county-level PH variation among T2DM patients across eight years (2010-2017), four years (2010-2013) before the Medicaid expansion and the next four years (2014-2017) after the implementation of Medicaid expansion to estimate the ACA impact on health outcomes among T2DM patients in Kentucky. County-level T2DM-PH rates reflect health access outcome variables. In this analysis, descriptive statistics and geographic mapping were employed.

The second phase focused on objective number two, to analyze and compare the socioeconomic factors association with T2DM-PH rates Pre- and Post-Medicaid expansion. County level predisposing factors such as age, degree of urbanization, primary care and general preventive care, were designated social factors. County-level enabling factors such as income, poverty, and percent of uninsured were economic factors. All county level socioeconomic factors were extracted from the AHRF data (2010-2017) and merged with Kentucky Hospital Inpatient Discharge Databases (KID) (2010-2017) to estimate and compare the correlations pre- and post-Medicaid expansion. To analyze these correlations, principal components analysis, geographic mapping, and linear regression were employed.

\section{Data sources}

This study used two data sets, KID and AHRF. The KID during 2010-2017 which is managed by Kentucky Cabinet for Health and Family Services (KCHFS). The data set consisted of a collection of records, each of which describes a single inpatient stay in a Kentucky hospital. Each record in the data set includes demographic information such as county Federal Information Processing Standards (FIPS) code of residence, length of stay 
(days), diagnoses coded using the International Classification of Diseases ICD9/10, and discharge year. The data included sufficient variables to conduct this research analysis of the county geospatial distribution of T2DM-PH Pre- and Post-Medicaid expansion in Kentucky.

\section{Table 7: Exclusion and Inclusion Criteria:}

\begin{tabular}{|l|l|l|}
\hline \multicolumn{1}{|c|}{ Observations Exclusion Stages } & Subtracted & Total \\
\hline Total number of hospitalizations available in the dataset (2010- & & $4,859,199$ \\
\hline $\begin{array}{l}\text { Observations whose residences are in other states (Indiana, } \\
\text { Ohio, Virginia etc) were excluded }\end{array}$ & 18,213 & $4,840,986$ \\
\hline $\begin{array}{l}\text { Observations without ICD9/10 codes indicating principal } \\
\text { diagnosis of T2DM (long-term complications, short-term } \\
\text { complications, uncontrolled, or lower-extremity amputation } \\
\text { among patients with T2DM) were excluded. }\end{array}$ & & 53,514 \\
\hline Observations without FIPS code were excluded & 983 & \\
\hline Total number of observations in the study & & 52,531 \\
\hline
\end{tabular}

County level T2DM-PH rates before and after the implementation of the Medicaid expansion were extracted from KID using county Federal Information Processing Standards (FIPS) and the groups of ICD-9 and ICD-10 conditions for PQI\#1 (short-term T2DM complications), PQI\#3 (long-term T2DM complications), PQI\# 14 (uncontrolled T2DM without complications), and PQI\# 16 (lower-extremity amputation among patients with T2DM) (see Table 8). 
Table 8: The ICD-9 and ICD-10 codes of AHRQ T2DM-PH.

\begin{tabular}{|c|c|c|}
\hline AHRQ T2DM-PH & ICD9 & ICD10 \\
\hline $\begin{array}{l}\text { PQI\#1: Short-term T2DM } \\
\text { complications }\end{array}$ & $\begin{array}{l}25003,25010,25012,25020,25022, \\
25030,25032\end{array}$ & $\begin{array}{l}\text { E1100, E1101, E11641, E1110, and } \\
\text { E1111 }\end{array}$ \\
\hline $\begin{array}{l}\text { PQI\#3: Long-term T2DM } \\
\text { complications }\end{array}$ & $\begin{array}{l}25040,25042,25072,25080,25050 \\
25052,25060,25062,25082,25090 \\
25092\end{array}$ & $\begin{array}{l}\text { E1121, E1122, E1129, E11311, } \\
\text { E11319, E11321, E113211, } \\
\text { E113212, E113213, E113219, } \\
\text { E11329, E113291, E113292, } \\
\text { E113293, E113299, E11331, } \\
\text { E11331, E113312, E113313, } \\
\text { E113319, E11339, E11339, } \\
\text { E113392, E113393, E113399, } \\
\text { E11341, E113411, E113412, } \\
\text { E113413, E113419, E11349, } \\
\text { E113491, E113492, E113493, } \\
\text { E113499, E11351, E113511, } \\
\text { E113512, E113513, E113519, } \\
\text { E113521, E113522, E113523, } \\
\text { E113529, E113531, E113532, } \\
\text { E113533, E113539, E113541, } \\
\text { E113542, E113543, E113549, } \\
\text { E113551, E113552, E113553, } \\
\text { E113592, E113559, E11359, } \\
\text { E113591, E113593, E113599, } \\
\text { E1136, E1137X1, E1137X2, } \\
\text { E1137X3, E1137X9, E1139, E1140, } \\
\text { E1141, E1142, E1143, E1144, } \\
\text { E1149, E1151, E1152, E1159, } \\
\text { E11610, E11618, E11620, E11621, } \\
\text { E11622, E11628, E11630, E11638, } \\
\text { E1169, E118 }\end{array}$ \\
\hline $\begin{array}{l}\text { PQI\# 14: Uncontrolled T2DM } \\
\text { without complications }\end{array}$ & 25002,25003 & E1165, E1110, E1111, E11649 \\
\hline $\begin{array}{l}\text { PQI\# 16: Lower-extremity } \\
\text { amputation among patients with } \\
\text { T2DM }\end{array}$ & $\begin{array}{l}8410,8411,8412,8413,8414,8415 \\
8416,8417,8418,8419\end{array}$ & $\begin{array}{lll}\text { 0Y620ZZ, } & \text { 0Y6M0Z5, } & \text { 0Y630ZZ, } \\
\text { 0Y6M0Z6, } & \text { 0Y640ZZ, } & \text { 0Y6M0Z7, } \\
\text { 0Y670ZZ, } & \text { OY6M0Z8, } & \text { OY680ZZ, } \\
\text { 0Y6M0Z9, } & \text { 0Y6C0Z1, } & \text { 0Y6M0ZB, } \\
\text { 0Y6C0Z2, } & \text { 0Y6M0ZC, } & \text { 0Y6C0Z3, } \\
\text { 0Y6M0ZD } & \\
\end{array}$ \\
\hline
\end{tabular}

The second dataset used in this study was the Area Health Resources Files (AHRF). AHRF consists of comprehensive variables relating to county level health facilities, measures of resource scarcity, county health status, socioeconomic and environmental characteristics containing a variety of health care utilization, health professions and 
facilities, environmental, and socio-demographic information (Resources \& Administration, 2014).

For this study, county level socioeconomic data were extracted from AHRF databases and merged to KID dataset Pre- and Post-Medicaid expansion. The following variables were used as keys in the merge procedure: FIPS county code and year. This data source is updated with the most recent U.S. Census Bureau decennial and American Community Survey data. Multiple studies confirm the validity of these datasets (Nkem, 2014).

\section{Study population:}

The county level data for this study consisted of the adult residents' ages 18 years and older in 120 counties in Kentucky who were hospitalized for a principal diagnosis of one or more of T2DM complications at least once during 2010-2017. The research focused on the county adult population (18 years and older) because they are the most likely to encounter T2DM and access barriers to health services. Most current state and national efforts to expand healthcare coverage are focused on adult population. 


\section{Statistical Methods}

The two goals of this study are to analyze the county level geography and socioeconomic factors with the objective of predicting county level T2DM-PH rates before and after Medicaid expansion in Kentucky. Several statistical techniques were used to carry out the study's objectives:

Objective 1: Determine county level variation in T2DM-PH rates in Kentucky before ACA (2010-2013) and after ACA implementation (2014-2017).

- Descriptive analysis

- Geographic mapping for T2DM-PH rates

- Cluster analysis

Objective 2: Determine the relationship between county level socioeconomic factors and county level T2DM-PH rates before ACA (2010-2013) and after ACA implementation (2014-2017) in Kentucky.

- Principal components analysis (PCA)

- Geographic mapping for Principal Components (PCs) scores

- Ordinary Least Squares (OLS) regression

\section{Descriptive statistics:}

Univariate and bivariate analysis of the data were done using SPSS.

\section{Geographic mapping for T2DM-PH rates:}

After calculating the Pre- and Post-ACA county T2DM-PH rates and stated as a percent using IBM SPSS V25, Kentucky Geographic Information System (GIS) shapefiles were obtained from the Commonwealth Office of Technology. Shapefiles as geospatial vector 
data stored as points, lines, and polygons, used by GIS software (i.e., ArcGIS). Two maps were created and labeled to compare the spatial distribution of county T2DM-PH rates Preand Post-Medicaid expansion in Kentucky State. Shapefiles associated study data attributes, constitute the geographic information that was employed to create maps in the analysis.

\section{Cluster analysis:}

Cluster analysis was used to test the hypothesis of the county T2DM-PH variations Preand Post-Medicaid expansion (Table 9). Cluster analysis identify spatial clusters of counties with high or low T2DM-PH rates.

Table 9: County T2DM-PH variations hypotheses

\begin{tabular}{|l|l|}
\hline Null Hypothesis 1: & $\begin{array}{l}\text { Counties with high T2DM-PH rates are randomly } \\
\text { distributed across the state before the Medicaid expansion. }\end{array}$ \\
\hline Alternative Hypothesis 1: & $\begin{array}{l}\text { Counties with high T2DM-PH rates are not randomly } \\
\text { distributed across the state before and after the Medicaid } \\
\text { expansion. }\end{array}$ \\
\hline
\end{tabular}

\begin{tabular}{|l|l|}
\hline Null Hypothesis 2: & $\begin{array}{l}\text { Counties with high T2DM-PH rates are randomly } \\
\text { distributed across the state after the Medicaid expansion. }\end{array}$ \\
\hline Alternative Hypothesis 2: & $\begin{array}{l}\text { Counties with high T2DM-PH rates are not randomly } \\
\text { distributed across the state after the Medicaid expansion. }\end{array}$ \\
\hline
\end{tabular}


The shapefiles associated and study data attributes was employed using ArcGIS software. ArcGIS illustrates the degree of spatial autocorrelation for all T2DM-PH rates across counties. The cluster analysis calculates a local Moran's I value, z-score, p-value, and a code representing the cluster type for each statistically significant county Pre- and Post-Medicaid expansion. The computed Anselin local Moran's Index identifies concentrations of high values, concentrations of low values of county T2DM-PH rates. In other words, it measures the similarities and differences in T2DM-PH rates among contiguous counties (Boissy et al., 2011; Peach, Yaliraki, Lefevre, \& Barahona, 2019). The computed z-scores and p-values of each county are used to measure the statistical significance of the identified similarities (clusters) in T2DM-PH rates across counties (Zou, Peng, Wan, Mamady, \& Wilson, 2014).

Cluster analysis output includes maps with significant cluster types of High-High (HH), High-Low (HL), Low-High (LH), and Low-Low (LL) (see Table 10). Cluster type $\mathrm{HH}$ indicates statistical significance (positive Moran's Index, high positive z-score, $\mathrm{p}<0.005)$ clusters of counties with high T2DM-PH rates. Cluster type LL is for a statistical significance (positive Moran's Index, high positive z-score, $\mathrm{p}<0.005$ ) cluster of counties with low T2DM-PH rates (Nkem, 2014) (Table 10).

Table 10: Cluster analysis output

\begin{tabular}{|l|l|l|l|}
\hline \multicolumn{1}{|c|}{ Cluster Type } & \multicolumn{1}{|c|}{ Moran's Index } & \multicolumn{1}{|c|}{ z-score } & \multicolumn{1}{c|}{ p value } \\
\hline HH & Positive & Positive & $\mathrm{p}<0.005$ \\
\hline LL & Positive & Positive & $\mathrm{p}<0.005$ \\
\hline
\end{tabular}




\section{Principal Components Analysis (PCA):}

After the county T2DM-PH rates and clusters were calculated and mapped, county level characteristics were analyzed to identify the ecology factors related to T2DM-PH incidence. County level socioeconomic variables were retrieved from AHRF and linked to 120 counties' T2DM-PH rates before and after Medicaid expansion accordingly. Variables were selected based on data observation and prior literature. Many variables were highly inter-correlated, particularly economic variables. Due to highly correlated social and economic variables, PCA was used to reduce the dimension of a large set of socioeconomic variables to a small set that still contains most of the information in the large set (Plant, 2018; Smith, 2002). PCA was also employed to identify the county level socioeconomic patterns across 120 counties before and after Medicaid expansion. The analysis includes mathematical procedures that transform a number of (possibly) correlated variables into a (smaller) number of uncorrelated synthetic variables called principal components (PCs) (Plant, 2018; Smith, 2002). In the present study, the investigated socioeconomic variables included income based variables, urban-rural variables, medical care variables, and demographic variables.

In the final analysis, a set of twelve social and economic variables were selected to include in the PCA. Specifically, income based variables such as household income, percentage in poverty, income per capita, percentage of uninsured people, and unemployment rate were included. Additionally, social factors such as population size, urbanization rate, primary care physician (PCP) and general preventive care available, percent of population aged 65 and above, and median age were also included. All variables are aggregated to the county level. These were chosen because they are established 
indicators of medical availability and socioeconomic variation within a county. PH usually occur among the poor, chosen variable measure poverty and lack of poverty

\section{Proportion of variance that the components explain}

The PCA technique generates synthetic variables called principal components (PCs) for the dataset Pre/Post Medicaid expansion. Each PC is associated with an eigenvalue which determines the variation explained by PCs of the data Pre/Post Medicaid expansion. PCs are new variables that are constructed as a linear combinations of the initial variables, in a way to squeeze or compress information into the first components (Plant, 2018). The minimum number of principal components that account for most of the variation in socioeconomic data were determined by using the proportion of variance that the components explain.

\section{Eigenvalues and scree plot}

PCA of 12 dimensional data produced 12 PCs, where the maximum possible information were assigned in the first $\mathrm{PC}$, then maximum remaining information in the second and so on. The size of the eigenvalue determines the number of PCs selected (Plant, 2018). PCs with the largest eigenvalues were retained because they contain most of the information. The scree plot was used to show eigenvalues $>2.0$, from largest to smallest. The ideal pattern is a steep curve, followed by a bend or "elbow", and then a straight line. The components in the steep curve before the first point that starts the line trend were selected. 


\section{PCs score}

After the PCs Pre/Post Medicaid expansion were selected, each county's PCs score was computed, and used in subsequent outcome analyses.

\section{Geographic Mapping for PCs scores}

After determining the important PCs for the subsequent analyses, the tertile of each of the PC scores was calculated and mapped using ArcGIS. Counties' PC scores Pre- and PostMedicaid expansion were stored as polygons in shapefile and used by ArcGIS software. Two maps were created and labeled to show the spatial distribution of socioeconomic factors weights within a county Pre- and Post-Medicaid expansion in Kentucky State.

\section{Ordinary Least Squares (OLS) regression:}

Linear regression using ordinary least squares was conducted to investigate whether or not the derived PCs (independent variables) predict the county T2DM-PH rate (dependent variable) across 120 counties before and after Medicaid expansion. OLS regression is a powerful technique for modeling continuous data. The following regression equation was used: $y=b^{*} x+c$; where $y=$ estimated dependent variable, $c=$ intercept (constant), $b=$ regression coefficient and $\mathrm{x}=$ independent variable. For statistically significant models, for every one-unit increase in the predictor, the dependent variable will increase or decrease by a unit as indicated by regressions slopes $\mathrm{p}<0.05$, beta coefficients. For example, the PCs scores are standardized and, therefore, one unit is a standard deviation. 


\section{Measured Variables:}

Dependent variable: county level T2DM-PH rates Pre/Post Medicaid expansion. The present study used the PQI composites of T2DM admissions as the numerator which include admissions for patients' age 18 years and older, that met the inclusion and exclusion rules in any of the following PQIs:

- PQI \#1 T2DM Short-Term Complications Admission Rate

- PQI \#3 T2DM Long-Term Complications Admission Rate

- PQI \#14 Uncontrolled T2DM Admission Rate

- PQI \#16 Lower-Extremity Amputation among Patients with T2DM Rate.

The denominator represents county mid-year population. Discharges in the numerator are assigned to the denominator based on the patient residence, not the county of the hospital where the discharge occurred (Agency for Healthcare Research and Quality Indicators, 2002).

Independent variables: Counties' socioeconomic PCs loaded with: income per capita, percentage of uninsured people, percent of urban population, primary care and general preventive cares, population aged 65 and above, and median age, household income, percentage in poverty, and unemployment rate. All county socioeconomic variables were extracted from AHRF before and after Medicaid expansion (2010-2017) (see Table 11). 
Table 11: County level T2DM-PH and socioeconomic measures

\begin{tabular}{|c|c|c|c|}
\hline Measured Variables & Definitions & \begin{tabular}{|l} 
Variables \\
Types
\end{tabular} & \begin{tabular}{|l|} 
Data \\
Sources
\end{tabular} \\
\hline \multicolumn{4}{|l|}{ Dependent Variables } \\
\hline $\begin{array}{l}\text { County level rates of } \\
\text { T2DM-PH in } \\
\text { Kentucky State } \\
\end{array}$ & $\begin{array}{l}\text { County estimates of the total number of times a patient was } \\
\text { hospitalized T2DM as identified by AHRQ as PQI / Total number of } \\
\text { the county mid-year population }\end{array}$ & $\begin{array}{l}\text { Continuous } \\
\text { variable }\end{array}$ & $\begin{array}{l}\text { KID } \\
(2010-2017)\end{array} \mid$ \\
\hline \multicolumn{4}{|c|}{ Independent Variables } \\
\hline $\begin{array}{l}\text { Socioeconomic } \\
\text { Factors }\end{array}$ & $\begin{array}{l}\text { Counties' socioeconomic PCs loaded with: Income per capita, } \\
\text { percentage of uninsured people, percent of urban population, primary } \\
\text { care and general preventive offices, population aged } 65 \text { and above, } \\
\text { and median age, household income, percentage in poverty, and } \\
\text { unemployment rate. }\end{array}$ & $\begin{array}{l}\text { Continuous } \\
\text { variables }\end{array}$ & $\left|\begin{array}{l}\text { AHRF } \\
(2010-2017)\end{array}\right|$ \\
\hline
\end{tabular}

\section{Data Management}

The study's objectives were tested using county-level data estimates managed by the principal investigator. All data and electronic study materials were saved in a secured and encrypted computer, protected by a password, and accessible only to the principal investigator. The secured computer was protected by antivirus/malware application. All data manipulation, mapping, and statistical analyses were conducted using Microsoft Excel (Microsoft Corporation, Redmond, WA), ArcGIS (Esri, Redlands, CA), and SPSS (IBM SPSS V.25). Data analysis followed the AHRQ guidelines for "Using Administrative Data to Monitor, Access, Identify Disparities, and Assess Performance of the Safety-Net" manuscript (Nkem, 2014). 


\section{Summary}

Table 12 summarizes the statistical techniques and variables used to satisfy the study objectives.

Table 12: Objectives and Statistical Analyses Plan

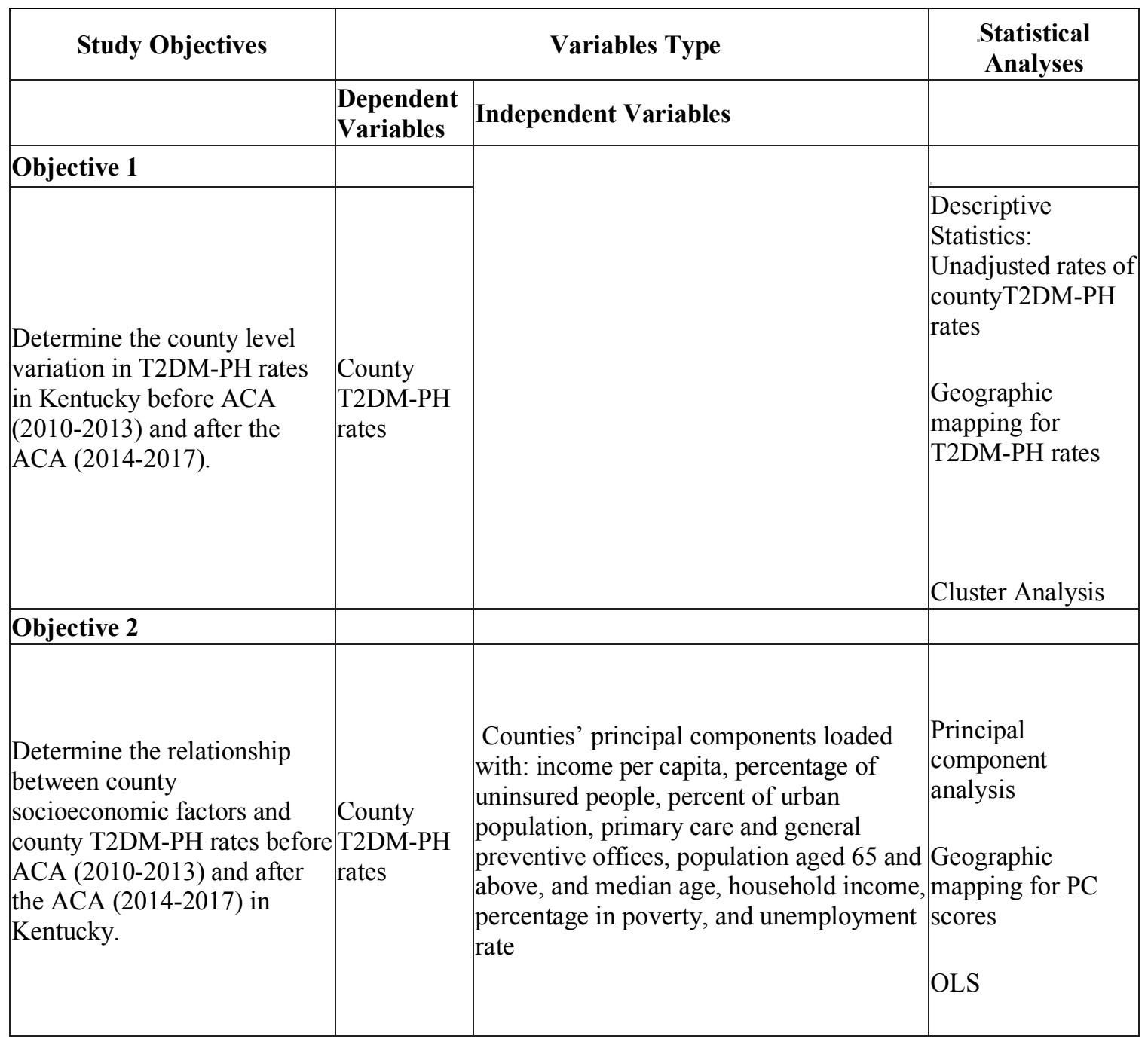


CHAPTER IV

RESULTS

\section{Descriptive Analysis:}

From 2010-2017, there were 52,531 T2DM-PH KID records eligible for our study. $54 \%(28,467)$ of all eligible T2DM-PH KID records occurred before the Medicaid expansion 2010-2013, and 46\% $(24,064)$ occurred after the Medicaid expansion 20142017. When the overall T2DM-PH rates Pre- and Post-ACA were assessed, a significant reduction $(8.38 \%)$ in $\mathrm{T} 2 \mathrm{DM}-\mathrm{PH}$ discharges rates was found in the period of the postexpansion $(\mathrm{P}=0.001)$. The population characteristics assessment showed that in the male population, Pre- and Post-Medicaid expansion accounts for (54\% versus 57\%) compared to the female population (46\% versus 43\%) (Table 13). Also, the T2DM-PH rates Pre-and Post-ACA were higher in the 61 years and above age group (46\% versus $52 \%$ ) than in the 41-60 (42\% versus 45\%) and 21-40 (11\% versus 3\%) age groups (Table 13). Additionally, the data assessment revealed a significant decline in the average uninsured rate across 120 counties. The uninsured rate declined from $22.1 \%$ (Pre-ACA) to $10.4 \%$ (Post-ACA) ( $\mathrm{p}=$ 0.001). However, there was no significant change in average poverty rate across Kentucky counties Pre-ACA (21.12\%) and Post-ACA (21.04\%) $(\mathrm{p}=0.691)($ Table 13).

\section{Table 13: Descriptive assessment of T2DM-PH Pre-and Post-Medicaid expansion}




\begin{tabular}{|c|c|c|c|c|}
\hline & \multicolumn{2}{|c|}{$\begin{array}{c}\text { Pre-Medicaid expansion } \\
(2010-2013)\end{array}$} & \multicolumn{2}{|c|}{$\begin{array}{c}\text { Post-Medicaid expansion } \\
(2014-2017)\end{array}$} \\
\hline & Non T2DM-PH & T2DM-PH & Non T2DM-PH & T2DM-PH \\
\hline Hospitalization & $2,553,168$ & 28,467 & $2,412,308$ & 24,064 \\
\hline Gender & $\begin{array}{l}\text { Male }(42 \%) \\
\text { Female }(58 \%)\end{array}$ & $\begin{array}{l}\text { Male }(54 \%) \\
\text { Female }(46 \%)\end{array}$ & $\begin{array}{l}\text { Male }(43 \%) \\
\text { Female }(57 \%)\end{array}$ & $\begin{array}{l}\text { Male }(57 \%) \\
\text { Female }(43 \%)\end{array}$ \\
\hline Age & $\begin{array}{l}61 \text { and above } \\
(42 \%) \\
41-60(26 \%) \\
21-40(19 \%) \\
\end{array}$ & $\begin{array}{l}61 \text { and above } \\
(46 \%) \\
41-60(44 \%) \\
21-40(12 \%) \\
\end{array}$ & $\begin{array}{l}61 \text { and above }(39 \%) \\
41-60(28 \%) \\
21-40(20 \%)\end{array}$ & $\begin{array}{l}61 \text { and above }(52 \%) \\
41-60(45 \%) \\
21-40(3 \%) \\
\end{array}$ \\
\hline $\begin{array}{l}\text { Health } \\
\text { coverage }\end{array}$ & $\begin{array}{l}\text { Private }(52 \%) \\
\text { Public(28\%) } \\
\text { Uninsured(14\%) }\end{array}$ & $\begin{array}{l}\text { Private(19\%) } \\
\text { Public(69\%) } \\
\text { Uninsured(11\%) }\end{array}$ & $\begin{array}{l}\text { Private(48\%) } \\
\text { Public(39\%) } \\
\text { Uninsured(6\%) }\end{array}$ & $\begin{array}{l}\text { Private(18\%) } \\
\text { Public(79\%) } \\
\text { Uninsured(2\%) }\end{array}$ \\
\hline Poverty rate & \multicolumn{2}{|c|}{21.12 percent } & \multicolumn{2}{|c|}{21.04 percent } \\
\hline
\end{tabular}

\section{Geographic mapping for T2DM-PH rates:}

The county T2DM-PH rates Pre- and Post-Medicaid expansion were compared across 120 counties in Kentucky States. The T2DM-PH rates across the 120 counties significantly decreased in the Post-Medicaid expansion period $(\mathrm{p}=0.002)$. Figure 1 shows the rates of T2DM-PH across counties in Kentucky before and after the expansion. The red scale represents the rate range of county's T2DM-PH rate. Darker colors represents higher T2DM-PH rates. The highest rates of T2DM-PH during the period of the Pre-expansion were in counties in the south, east and southeastern Kentucky (i.e., Bell, Green, Harlan, Letcher, Clay, and Owsley, Breathitt, Leslie, Lawrence, Fulton) with a rate range of 16 24 T2DM-PH per 1000. Counties with the low rates of T2DM-PH were distributed across the state, ranging from 4-7 hospitalizations per 1000 as it is shown in the map (Figure 1). Similar to county T2DM-PH rates Pre-expansion, the highest counties' T2DM-PH rates Post-expansion were also in southeast Kentucky (i.e. Bell, Harlan, Letcher, Lawrence, Leslie Fulton, and Clay) with a slightly lower rate range of 16-18 T2DM-PH per 1000. 
Counties with the lowest rates of T2DM-PH Pre- and Post-ACA were distributed across the state with an average rate of 4-7 hospitalization per 1000).

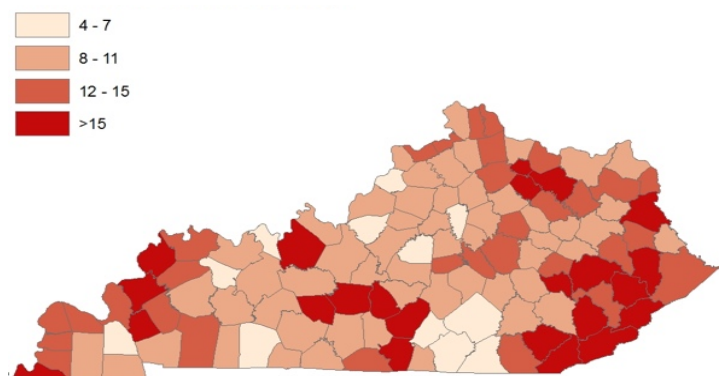

(a)

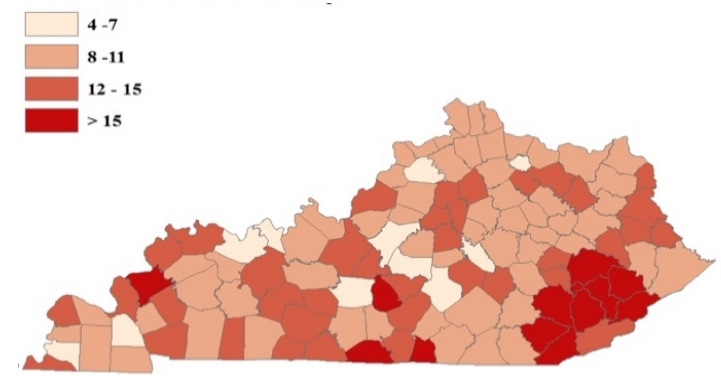

(b)

Figure 1: Counties' T2DM-PH rates per 1000 Pre-ACA (a) Post-ACA (b) in Kentucky

Table 14 shows the twenty highest T2DM-PH rates and uninsured rate Pre- and Post-ACA across counties in Kentucky. All the counties had a decline in T2DM-PH and uninsured rates Post-ACA. The rate of the decline varied, but all the counties with the largest changes were located in the southeast region of the State (i.e., Breathitt, Leslie, Breckinridge, and Edmonson). The exception is Green County, which is in south Kentucky. 
Table 14: Top 20 counties with T2DM-PH rates Pre- and Post-Medicaid expansion

\begin{tabular}{|l|r|r|r|r|r|}
\hline \multicolumn{1}{|c|}{ County } & $\begin{array}{c}\text { T2DM-PH Rates } \\
\text { Pre-ACA/1000 }\end{array}$ & $\begin{array}{c}\text { T2DM-PH Rates } \\
\text { Post-ACA/1000 }\end{array}$ & $\begin{array}{c}\text { T2DM-PH Rates } \\
\text { Change }\end{array}$ & $\begin{array}{c}\text { Uninsured rate } \\
\text { Pre-ACA }\end{array}$ & $\begin{array}{c}\text { Uninsured } \\
\text { rate Post-ACA }\end{array}$ \\
\hline Breathitt & 23.6 & 17.7 & -5.9 & 25.5 & 9.4 \\
\hline Green & 23.5 & 17.6 & -5.9 & 20.2 & 9.9 \\
\hline Leslie & 22.7 & 16.4 & -6.4 & 21.7 & 9.8 \\
\hline Lawrence & 17.1 & 12.2 & -4.9 & 20.3 & 9.1 \\
\hline Fulton & 17 & 12.3 & -4.6 & 19.5 & 8.1 \\
\hline Edmonson & 16.7 & 10.8 & -5.9 & 21.3 & 10.5 \\
\hline Owsley & 16.3 & 12 & -4.3 & 19.3 & 9.2 \\
\hline Crittenden & 15.7 & 14.1 & -1.6 & 19.6 & 8.7 \\
\hline Adair & 15.5 & 12 & -3.4 & 18.2 & 8.9 \\
\hline Cumberland & 15.4 & 11.6 & -3.8 & 18.2 & 10.6 \\
\hline Breckinridge & 15.4 & 8.7 & -6.6 & 22.1 & 12.3 \\
\hline Knott & 15 & 13.2 & -1.7 & 19.5 & 10.5 \\
\hline Fleming & 14.9 & 12.9 & -2 & 18.1 & 12.9 \\
\hline Knox & 14.7 & 13.1 & -1.6 & 18.4 & 11.2 \\
\hline Letcher & 13.9 & 14.3 & 0.4 & 18.8 & 11.8 \\
\hline Robertson & 13.8 & 6.9 & -6.9 & 21.9 & 14.9 \\
\hline Floyd & 13.6 & 9.8 & -3.8 & 19.6 & 10.3 \\
\hline Hart & 13.5 & 6.8 & -6.7 & 19.9 & 11.2 \\
\hline Bell & 13.4 & 12.2 & -1.2 & 18 & 11.9 \\
\hline Harlan & 13.4 & 12.8 & -0.6 & 19 & 12.4 \\
\hline
\end{tabular}

Objective Number 1: Variations in County-level Rates of Preventable Hospitalizations

In Kentucky before and after ACA:

\begin{tabular}{|l|l|}
\hline Null Hypothesis: & $\begin{array}{l}\text { Counties with high rates of preventable hospitalization due to } \\
\text { type } 2 \text { diabetes (T2DM-PH) are randomly distributed across } \\
\text { the state before and after the Medicaid expansion. }\end{array}$ \\
\hline Hypothesis: & $\begin{array}{l}\text { Counties with high rates of preventable hospitalization due to } \\
\text { type } 2 \text { diabetes (T2DM-PH) are not randomly distributed } \\
\text { across the state before and after the Medicaid expansion. }\end{array}$ \\
\hline
\end{tabular}

\section{Cluster analysis:}


The spatial statistics analysis revealed significant spatial clustering of counties with similar rates of T2DM-PH in the southeastern region before and after the expansion (Figure 2). This means counties with high T2DM-PH rates are not randomly distributed across Kentucky during both periods, Pre- and Post-expansion. Figure 2 depicts the T2DM-PH rates Pre- and Post-expansion with a spatial clustering across the State where neighboring counties with similar values are clustered together. The two maps in Figure 2 show statistically significant clustering of counties in the southeastern region of Kentucky, where the high T2DM-PH rate county is surrounded by high T2DM-PH rate counties. Counties with cluster type high-high $(\mathrm{HH})$ are high T2DM-PH rate counties significantly clustered around each other (high positive z-score, positive Moran's Index values and p-value $<0.05$ ) (Figure 2). Counties with cluster type low-low (LL) before and after the expansion are low T2DM-PH rates counties surrounded by low T2DM-PH rates counties (high positive zscore, positive Moran's Index values, and p-value $<0.05$ ) (Figure 2).

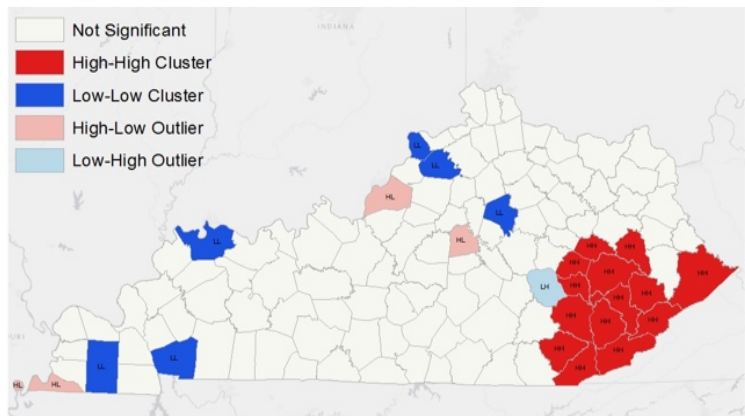

(a)

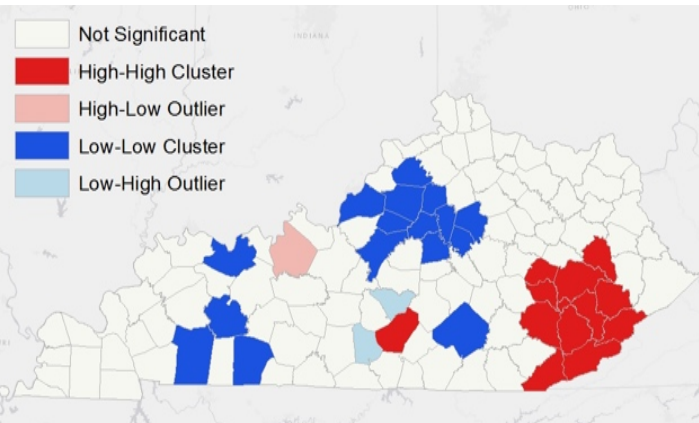

(b)

Figure 2 : Cluster analysis of T2DM-PH Pre-expansion (a) and Post-expansion (b)

\section{HH cluster}


The spatial autocorrelation analysis of the periods before and after the expansion found a significant $\mathrm{HH}$ cluster (positive z-score and positive Moran's Index value ( $\mathrm{p}$ $<0.05)$ ) (see Table 15 and 16). The significant HH cluster of T2DM-PH rates in both periods located in southeastern counties (i.e., Bell, Clay, Lee, Harlan, Magoffin, Letcher, Leslie, and Owsley) (Table 15-16, Figure 2). These counties had high T2DM-PH rates and significantly clustered around each other. A positive value for Moran's I and z-score indicate that a county has neighboring counties with similarly high T2DM-PH rates. Pvalues determine the statistical significance of the similarity in county T2DM-PH rate (Table 15-16). Using the analysis findings, the null hypothesis, that clustering of counties with high rates of T2DM-PH are randomly distributed across the State before and after the Medicaid expansion, was rejected.

Table 15: Cluster analysis Pre-Medicaid expansion

\begin{tabular}{|l|l|l|r|l|}
\hline County & $\begin{array}{l}\text { Local } \\
\text { Moran's } \\
\text { I index }\end{array}$ & $\begin{array}{l}\text { Local } \\
\text { Moran's } \\
\text { I index } \\
\text { Z-Score }\end{array}$ & $\begin{array}{l}\text { Local Moran's I } \\
\text { index P-Value }\end{array}$ & $\begin{array}{l}\text { Cluster } \\
\text { Type }\end{array}$ \\
\hline Knox & 3.71948 & 2.84497 & 0.006 & HH \\
\hline Bell & 22.1037 & 4.66672 & 0.002 & HH \\
\hline Clay & 26.3733 & 4.63985 & 0.002 & HH \\
\hline Lee & 9.22439 & 2.27382 & 0.024 & HH \\
\hline Harlan & 31.243 & 6.1622 & 0.002 & HH \\
\hline Wolf & 2.91693 & 2.18715 & 0.024 & HH \\
\hline Magoffin & 5.99527 & 2.82798 & 0.012 & HH \\
\hline Letcher & 22.0192 & 4.65401 & 0.002 & HH \\
\hline Perry & 61.9237 & 7.60511 & 0.002 & HH \\
\hline Pike & 2.29751 & 3.00084 & 0.008 & HH \\
\hline Knott & 16.5989 & 5.27201 & 0.002 & HH \\
\hline Breathitt & 4.29241 & 3.19194 & 0.01 & HH \\
\hline
\end{tabular}

Table 16: High-high (HH) cluster analysis Post-Medicaid expansion 


\begin{tabular}{|l|l|l|r|l|}
\hline County & $\begin{array}{l}\text { Local } \\
\text { Moran's } \\
\text { I index }\end{array}$ & $\begin{array}{l}\text { Local } \\
\text { Moran's } \\
\text { I index } \\
\text { Z-Score }\end{array}$ & $\begin{array}{l}\text { Local Moran's I } \\
\text { index P-Value }\end{array}$ & $\begin{array}{l}\text { Cluster } \\
\text { Type }\end{array}$ \\
\hline Bell & 1.63107 & 3.36038 & 0.006 & $\mathrm{HH}$ \\
\hline Clay & 0.72351 & 3.5224 & 0.012 & $\mathrm{HH}$ \\
\hline Lee & 0.4429 & 2.34633 & 0.03 & $\mathrm{HH}$ \\
\hline Harlan & 2.96226 & 3.72429 & 0.002 & $\mathrm{HH}$ \\
\hline Magoffin & 0.62303 & 2.66851 & 0.024 & $\mathrm{HH}$ \\
\hline Letcher & 1.44578 & 2.45715 & 0.03 & $\mathrm{HH}$ \\
\hline Perry & 3.85863 & 5.48668 & 0.002 & $\mathrm{HH}$ \\
\hline Knott & 1.65759 & 3.54271 & 0.002 & $\mathrm{HH}$ \\
\hline Adair & 0.61787 & 2.64325 & 0.024 & $\mathrm{HH}$ \\
\hline Leslie & 4.54762 & 3.01595 & 0.018 & $\mathrm{HH}$ \\
\hline
\end{tabular}

\section{LL cluster}

The analysis found a significant LL clustering of counties with low T2DM-PH rates (LL) before and after the expansion (Table 17-18, Figure 2). Significant positive z-scores and Moran's Index values $(\mathrm{p}<0.05)$ in cluster of counties with low T2DM-PH rates were found during the Pre- and Post-expansion periods. Henry, Henderson, and Graves were LL clusters in the north and west regions of the State Pre-ACA (Table 17, Figure 2). Counties in central north and west (i.e., Oldham, Shelby, Spencer, and Fayette) were LL cluster PostACA (Table 18, Figure 2).

Table 17: Low-low (LL) cluster analysis Pre-Medicaid expansion 


\begin{tabular}{|l|r|l|r|l|}
\hline County & $\begin{array}{l}\text { Local } \\
\text { Moran's } \\
\text { I index }\end{array}$ & $\begin{array}{l}\text { Local } \\
\text { Moran's } \\
\text { I index } \\
\text { Z-Score }\end{array}$ & Local Moran's I index P-Value & $\begin{array}{l}\text { Cluster } \\
\text { Type }\end{array}$ \\
\hline Henry & 3.52336 & 1.55333 & 0.036 & LL \\
\hline Henderson & 2.449 & 1.33537 & 0.046 & LL \\
\hline Graves & 0.50819 & 1.41791 & 0.038 & LL \\
\hline
\end{tabular}

Table 18: Low-low (LL) cluster analysis Post-Medicaid expansion

\begin{tabular}{|l|c|c|r|l|}
\hline County & $\begin{array}{l}\text { Local } \\
\text { Moran's } \\
\text { I index }\end{array}$ & $\begin{array}{l}\text { Local } \\
\text { Moran's } \\
\text { I index Z- } \\
\text { Score }\end{array}$ & $\begin{array}{l}\text { Local Moran's I } \\
\text { index P-Value }\end{array}$ & $\begin{array}{l}\text { Cluster } \\
\text { Type }\end{array}$ \\
\hline Anderson & 0.39531 & 1.80511 & 0.002 & LL \\
\hline Logan & 0.256187 & 1.503181 & 0.014 & LL \\
\hline Jefferson & 0.198615 & 1.935009 & 0.002 & LL \\
\hline Franklin & 0.304724 & 1.708774 & 0.004 & LL \\
\hline Spencer & 0.521137 & 1.421625 & 0.02 & LL \\
\hline Henry & 0.415319 & 1.294116 & 0.024 & LL \\
\hline Nelson & 0.30933 & 1.820857 & 0.004 & LL \\
\hline Mercer & 0.196268 & 1.528301 & 0.012 & LL \\
\hline Muhlenberg & 0.331634 & 1.660758 & 0.008 & LL \\
\hline Fayette & 0.377173 & 1.468885 & 0.018 & LL \\
\hline Pulaski & 0.323383 & 1.344713 & 0.048 & LL \\
\hline
\end{tabular}

Table 19 summarizes the cluster analysis findings Pre- and Post-ACA 
Table 19: Cluster Analysis Interpretation

\begin{tabular}{|c|l|l|l|l|}
\hline Cluster Type & \multicolumn{1}{|c|}{ Statistics } & \multicolumn{1}{c|}{$\begin{array}{c}\text { Counties } \\
\text { Pre-ACA }\end{array}$} & \multicolumn{1}{c|}{$\begin{array}{c}\text { Counties } \\
\text { Post-ACA }\end{array}$} & Interpretations \\
\hline HH (Dark red) & $\begin{array}{l}\text { Positive Moran's } \\
\text { Index, High } \\
\text { Positive Z-score, } \\
\mathrm{p}<0.005\end{array}$ & $\begin{array}{l}\text { Southeast: } \\
\text { Harlan, Letcher, } \\
\text { Bell, Leslie, } \\
\text { Perry, Knott, } \\
\text { Magoffin, } \\
\text { Breathitt, } \\
\text { Owsley, and } \\
\text { Clay }\end{array}$ & $\begin{array}{l}\text { Southeast: } \\
\text { Harlan, Letcher, } \\
\text { Bell, Leslie, } \\
\text { Perry, Knott, } \\
\text { Magoffin, } \\
\text { Breathitt, } \\
\text { Owsley, Clay, } \\
\text { and Pike }\end{array}$ & $\begin{array}{l}\text { HIGH T2DM-PH } \\
\text { rate county } \\
\text { surrounded } \\
\text { by HIGH T2DM- } \\
\text { PH rats counties }\end{array}$ \\
& & $\begin{array}{l}\text { Henry, Graves, } \\
\text { and Henderson }\end{array}$ & $\begin{array}{l}\text { Spencer, Shelby, } \\
\text { Fayette, Henry, } \\
\text { Franklin, } \\
\text { Lelson, }\end{array}$ & $\begin{array}{l}\text { LOW T2DM-PH } \\
\text { rate county } \\
\text { surrounded } \\
\text { by LOW T2DM- } \\
\text { PH rats counties }\end{array}$ \\
& $\begin{array}{l}\text { Positive Moran's } \\
\text { Index, High } \\
\text { Positive Z-score, } \\
\text { p }<0.005\end{array}$ & & $\begin{array}{l}\text { Jefferson and } \\
\text { Scott }\end{array}$ & \\
& & &
\end{tabular}

Objective Number 2: Analyze the association of county-level socioeconomic profiles with differential rates of preventable hospitalization among type 2 diabetes (T2DMPH) patients before and after ACA implementation in Kentucky.

\section{Principal Components Analysis Pre-Post Medicaid expansion:}

PCA identified profiles of the number of primary care physicians, population density, total number of general preventive care, primary care facilities, population ages 65 and above, median age, income per capita, median household income, percent persons in poverty, percentage of people without health insurance, and unemployment rate. A cutoff of 75 percent of cumulative variation were used to select the number of principal components (PC) to include in subsequent outcome analyses. Tertile of each of the PC scores were derived and mapped in ArcGIS.

\section{PCs Pre-Post expansion}


During 2010-2013 and 2014-2017, two PCs Pre-expansion and two PCs Postexpansion accounted for over 75 percent of the variation in socioeconomic factors. The selected PCs for both periods had eigenvalues $>2$, and were above the elbow in the scree plot (Figure 3, Table 20-21). PC1 Pre- and Post-ACA explained 52.1 percent and 51.1 percent of the variation in socioeconomic factors, respectively. PC2 Pre and Post ACA explained an additional 23.4 percent and 25.1 percent of the variations respectively (Table 20 and 21). PC1 and PC2 Pre- and Post-ACA are the smaller number of components that explain the most variance, which was 75 percent of the county socioeconomic variance.

Table 20: Total variance explained of the PCA Pre ACA

\begin{tabular}{|l|c|c|r|r|r|r|}
\hline \multirow{2}{*}{ Component } & \multicolumn{3}{|c|}{ Initial Eigenvalues } & \multicolumn{3}{c|}{$\begin{array}{c}\text { Extraction Sums of Squared } \\
\text { Loadings }\end{array}$} \\
\cline { 2 - 7 } & Total & $\begin{array}{c}\text { \% of } \\
\text { Variance }\end{array}$ & $\begin{array}{c}\text { Cumulative } \\
\%\end{array}$ & Total & $\begin{array}{c}\text { \% of } \\
\text { Variance }\end{array}$ & $\begin{array}{c}\text { Cumulative } \\
\%\end{array}$ \\
\hline 1 & 6.530 & 52.113 & 52.113 & 6.530 & 52.113 & 52.113 \\
\hline 2 & 2.573 & 23.445 & 75.558 & 2.573 & 23.445 & 75.558 \\
\hline 3 & 1.009 & 8.408 & 84.267 & & & \\
\hline 4 & 0.748 & 6.231 & 90.498 & & & \\
\hline 5 & 0.514 & 4.284 & 94.782 & & & \\
\hline 6 & 0.338 & 2.814 & 97.596 & & & \\
\hline 7 & 0.137 & 1.142 & 98.738 & & & \\
\hline 8 & 0.088 & 0.737 & 99.475 & & & \\
\hline 9 & 0.052 & 0.431 & 99.905 & & & \\
\hline 10 & 0.007 & 0.061 & 99.966 & & & \\
\hline 11 & 0.005 & 0.025 & 99.991 & & & \\
\hline 12 & 0.003 & 0.009 & 100.000 & & & \\
\hline
\end{tabular}

Table 21: Total variance explained of the PCA Post ACA

\begin{tabular}{|l|c|c|c|c|c|c|}
\hline \multirow{2}{*}{ Component } & \multicolumn{3}{|c|}{ Initial Eigenvalues } & \multicolumn{3}{c|}{ Extraction Sums of Squared Loadings } \\
\cline { 2 - 7 } & Total & $\begin{array}{c}\text { \% of } \\
\text { Variance }\end{array}$ & $\begin{array}{c}\text { Cumulativ } \\
\mathrm{e} \%\end{array}$ & Total & $\begin{array}{c}\text { \% of } \\
\text { Variance }\end{array}$ & $\begin{array}{c}\text { Cumulative } \\
\%\end{array}$ \\
\hline 1 & 5.661 & 51.116 & 51.116 & 5.661 & 51.116 & 51.116 \\
\hline 2 & 2.745 & 25.167 & 76.283 & 2.745 & 25.167 & 76.283 \\
\hline 3 & 0.981 & 8.917 & 85.336 & & & \\
\hline 4 & 0.686 & 6.241 & 91.577 & & & \\
\hline 5 & 0.374 & 3.398 & 94.975 & & & \\
\hline 6 & 0.253 & 2.300 & 97.275 & & & \\
\hline 7 & 0.176 & 1.599 & 98.874 & & & \\
\hline 8 & 0.093 & 0.844 & 99.718 & & & \\
\hline 9 & 0.028 & 0.259 & 99.977 & & & \\
\hline 10 & 0.009 & 0.018 & 99.995 & & & \\
\hline 11 & 0.003 & 0.003 & 99.998 & & & \\
\hline 12 & 0.001 & 0.002 & 100.000 & & & \\
\hline
\end{tabular}




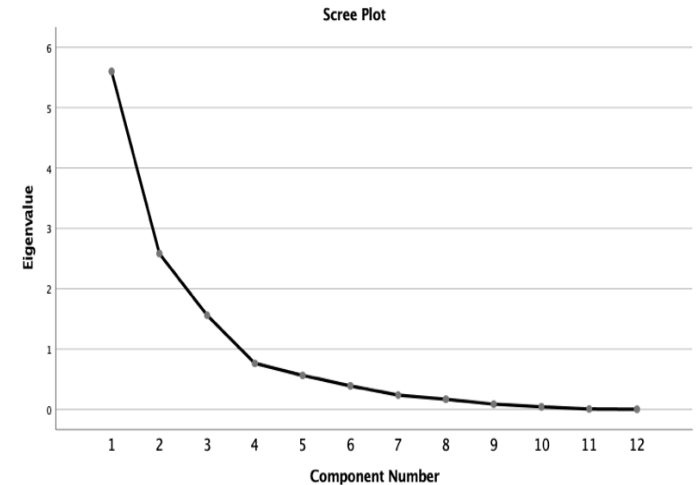

(a)

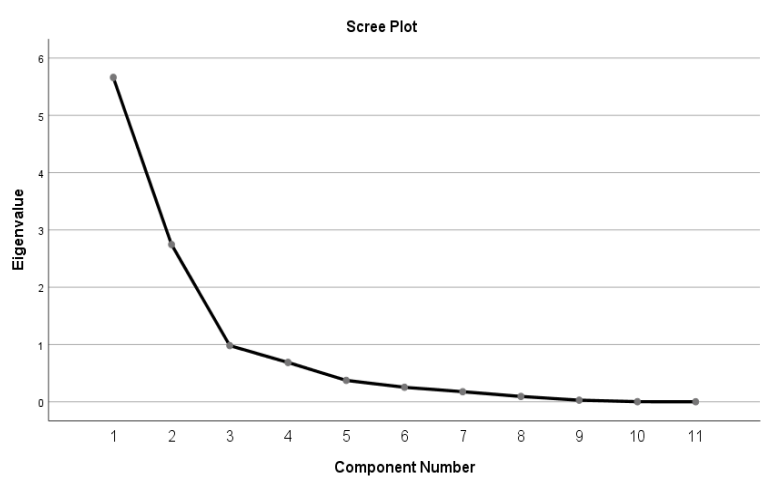

(b)

Figure 3: Scree plot for the PCA Pre-ACA (a) and Post-ACA (b)

To interpret the qualified PCs Pre- and Post-ACA, Table 22 shows the direction of the loading coefficients for the socioeconomic variables (Table 22). The direction (+ or -) indicates whether the variable contributes to increase or decrease in the PC. The larger the absolute value of the coefficient, the more important the corresponding variable is in calculating the component and higher score the county weight in that component.

Table 22: Structure matrix of the PCA Pre- and Post-ACA

\begin{tabular}{|l|c|c|c|c|}
\hline & $\begin{array}{c}\text { PC1 } \\
\text { Pre }\end{array}$ & $\begin{array}{c}\text { PC1 } \\
\text { Post }\end{array}$ & $\begin{array}{c}\text { PC2 } \\
\text { Pre }\end{array}$ & $\begin{array}{c}\text { PC2 } \\
\text { Post }\end{array}$ \\
\hline Population density & 0.988 & 0.993 & & -0.315 \\
\hline PCP & 0.986 & 0.982 & & \\
\hline Preventive care & 0.976 & 0.939 & -0.351 & -0.317 \\
\hline Primary care & 0.339 & 0.919 & & \\
\hline $\begin{array}{l}\text { Population aged 65 } \\
\text { and above }\end{array}$ & 0.976 & 0.986 & & \\
\hline $\begin{array}{l}\text { Per Capita Personal } \\
\text { Income }\end{array}$ & 0.472 & 0.352 & -0.785 & -0.872 \\
\hline $\begin{array}{l}\text { Median Household } \\
\text { Income }\end{array}$ & & & -0.94 & -0.923 \\
\hline $\begin{array}{l}\text { \% Persons in } \\
\text { Poverty }\end{array}$ & & & 0.893 & 0.836 \\
\hline \% Uninsured & & & 0.775 & 0.702 \\
\hline $\begin{array}{l}\text { Unemployment } \\
\text { Rate, }\end{array}$ & & & 0.776 & 0.690 \\
\hline Median age & -0.349 & -0.335 & 0.328 & 0.336 \\
\hline $\begin{array}{l}\text { \% Urban } \\
\text { Population }\end{array}$ & 0.585 & 0.575 & -0.65 & -0.691 \\
\hline
\end{tabular}


PC1 Pre- and Post-ACA were associated with large population size, high percent of urban population, access to primary care and general preventive care, and younger population (Table 22). On the other hand, PC2 Pre- and Post-ACA were associated with a high proportion of uninsured people, low household income, high percentage in poverty, low income per capita, high unemployment rate, small population size, low rate of urbanization (high rurality), limitation in primary and preventive care, and older population (Table 22). Each county has unique PC1 and PC2 scores Pre- and Post-ACA implementation based on the variables loading shown in Table 22.

\section{PC1}

Table 24 lists the counties with the highest PC1 scores. High PC1 scores Pre- and PostACA indicated larger population size and better access to health compared to counties with lower PC1 scores (Table 23-24). PC1 scores tertiles were derived and projected on two maps, Pre- and Post-ACA. Counties in tertile 3 had the highest PC1 scores Pre- and PostACA, and they were mostly in the north part of the State (i.e., Jefferson, Fayette, Kenton, Hardin, and McCracken) during both periods (Figure 4). Whereas, counties in tertile 1 and 2 had lower PC1 scores, were distributed across the State during both periods (Figure 4). Lower PC1 scores (tertile 1 and tertile 2) Pre- and Post-ACA defined counties with an older populations and limited access to primary care and general preventive care (Table 23-24). It was also noted that the loading variables in $\mathrm{PC} 1$ pre and post-ACA show that primary care became more associated with having resources and wealth. 
Table 23: PC1 scores Interpretations Pre- and Post-ACA

\begin{tabular}{|l|l|}
\hline \multicolumn{1}{|c|}{ Principal } & \multicolumn{1}{c|}{ Interpretations } \\
\hline High PC1 score & $\begin{array}{l}\text { Counties with high scores had larger population size, higher } \\
\text { percent of urban population, and better access to primary care } \\
\text { physician, general preventive care, and younger age. }\end{array}$ \\
\hline Low PC1 score & $\begin{array}{l}\text { Counties with low scores had higher percent of rurality, } \\
\text { limitation on access to primary care physician and general } \\
\text { preventive care, and older age. }\end{array}$ \\
\hline
\end{tabular}

Table 24: Highest 20 PC1 scores across counties Pre- and Post-Medicaid expansion

\begin{tabular}{|l|r|r|l|}
\hline County & PC1_preACA & PC1_postACA & Region \\
\hline Jefferson & 9.28812 & 9.18329 & Northern \\
\hline Fayette & 3.69115 & 3.96535 & Northern \\
\hline Kenton & 1.89327 & 1.36606 & Northern \\
\hline Warren & 1.01617 & 1.31557 & Southwestern \\
\hline Boone & 0.96547 & 1.23225 & Northern \\
\hline Hardin & 0.82518 & 1.16866 & Northern \\
\hline Daviess & 0.78682 & 0.8858 & Northwestern \\
\hline Campbell & 0.75884 & 0.72983 & Northern \\
\hline Madison & 0.63404 & 0.6918 & Northern \\
\hline McCracken & 0.59066 & 0.61439 & Western \\
\hline Hopkins & 0.55693 & 0.5273 & Western \\
\hline Christian & 0.53873 & 0.48875 & Southwestern \\
\hline Boyd & 0.49335 & 0.34302 & Northeastern \\
\hline Pike & 0.41451 & 0.33145 & Southeastern \\
\hline Pulaski & 0.41062 & 0.26955 & Southern \\
\hline Bullitt & 0.28048 & 0.26746 & Northern \\
\hline Laurel & 0.27354 & 0.24427 & Southern \\
\hline Jessamine & 0.26108 & 0.23669 & Northern \\
\hline Franklin & 0.23091 & 0.23557 & Northern \\
\hline Barren & 0.22294 & 0.22215 & Southern \\
\hline
\end{tabular}

These counties are: High income (low poverty) Most urbanized Better access to PCP Younger population. 


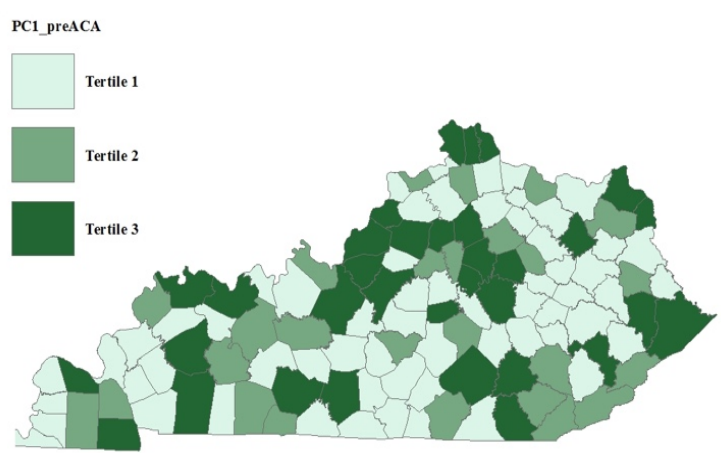

(a)

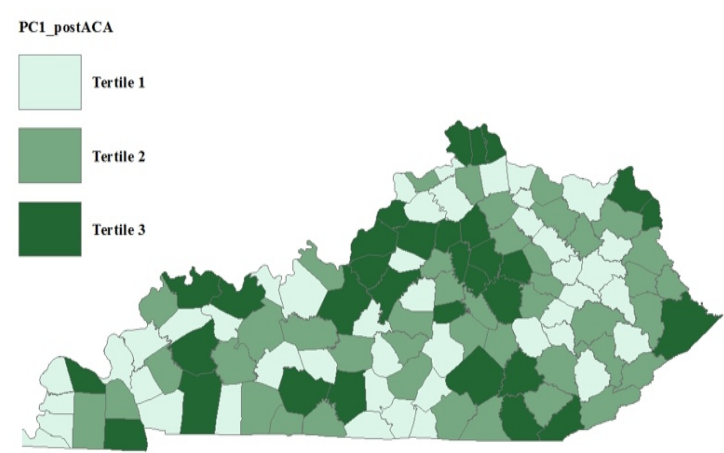

(b)

Figure 4: PC1 scores of the counties Pre-ACA (a) Post-ACA (b)

\section{PC2}

Table 26 lists counties with the highest PC2 scores. High PC2 scores Pre- and Post-ACA implementation indicated to an older population, and higher poverty and rurality compared to counties with a lower PC2 score (Table 25-26). Tertile of the PC2 scores were computed and plotted on two maps, Pre and Post ACA. Counties in tertile 3 had the highest PC2 scores, and they were mostly in the east and southeastern regions of the State (i.e., Magoffin, Owsley, Wolfe, Lee, Harlan, Leslie and Bell) (Figure 5) during both periods. Counties with low PC2 in tertile 1 were mostly in the north region of the State (i.e., Spencer, Shelby, Fayette, Jefferson, and Kenton) (Figure 5). Counties in tertile 2 were mostly in the south and west regions of Kentucky (Figure 5). Lower PC2 scores (tertile 1 and tertile 2) Pre- and Post-ACA defined counties with a lower proportion of uninsured people, better income, lower poverty, lower unemployment rate, and lower rate of rurality compared to the counties in tertile 3 (Table 25-26). 
Table 25: PCs scores Interpretations

\begin{tabular}{|l|l|}
\hline \multicolumn{1}{|c|}{ Principal } & \multicolumn{1}{|c|}{ Interpretations } \\
\hline High PC2 score & $\begin{array}{l}\text { Counties with high scores had higher proportion of uninsured } \\
\text { people, lower income, higher poverty rates, higher } \\
\text { unemployment rate, higher rurality, and older population. }\end{array}$ \\
\hline Low PC2 score & $\begin{array}{l}\text { Counties with low scores had lower proportion of uninsured } \\
\text { people, higher income, lower poverty rates, lower } \\
\text { unemployment rate, and urban population, and youger } \\
\text { population. }\end{array}$ \\
\hline
\end{tabular}

Table 26: Highest 20 PC2 scores across counties Pre- and Post-Medicaid expansion

\begin{tabular}{|l|r|r|l|}
\hline County & PC2 Pre-ACA & PC2 post-ACA & Region \\
\hline Magoffin & 2.42718 & 2.02747 & Eastern \\
\hline Owsley & 1.97408 & 1.89802 & Eastern \\
\hline Clay & 1.88551 & 1.7853 & Southeastern \\
\hline McCreary & 1.65017 & 1.6326 & Southeastern \\
\hline Bell & 1.52084 & 1.5172 & Southeastern \\
\hline Leslie & 1.50094 & 1.50981 & Southeastern \\
\hline Knott & 1.48268 & 1.48301 & Southeastern \\
\hline Lee & 1.45899 & 1.45844 & Eastern \\
\hline Harlan & 1.44956 & 1.39039 & Southeastern \\
\hline Wolfe & 1.43832 & 1.36649 & Eastern \\
\hline Letcher & 1.38441 & 1.34951 & Southeastern \\
\hline Martin & 1.36242 & 1.33564 & Eastern \\
\hline Menifee & 1.35862 & 1.31201 & Eastern \\
\hline Breathitt & 1.34614 & 1.29973 & Southeastern \\
\hline Jackson & 1.26376 & 1.25077 & Southeastern \\
\hline Knox & 1.26074 & 1.09983 & Southern \\
\hline Lewis & 1.23018 & 1.04265 & Eastern \\
\hline Elliott & 1.19839 & 1.00156 & Eastern \\
\hline Floyd & 1.14073 & 0.97971 & Southeastern \\
\hline Pike & 1.11751 & 0.89432 & Southeastern \\
\hline
\end{tabular}

These counties are:

Poorest

Most rural

Low access to PCP

Older population 


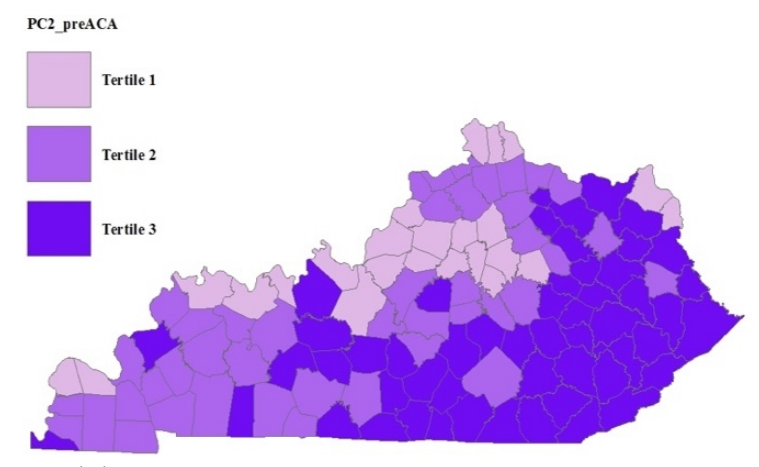

(a)

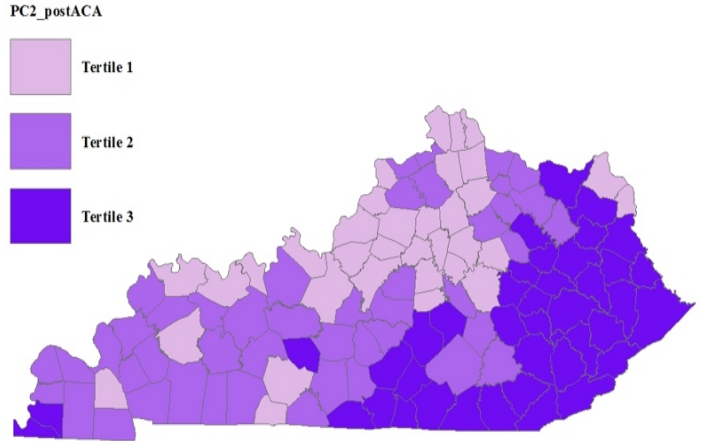

(b)

Figure 6: PC2 scores of the counties Pre-ACA (a) Post-ACA (b)

\section{Linear regression:}

Ordinary Least Squares (OLS) linear regression was used to estimate the association between the derived PCs and T2DM-PH rate across 120 counties Pre- and PostMedicaid expansion. PC1 and PC2 Pre- and Post-ACA were predictors of county T2DMPH rates. The relationship between county T2DM-PH rates and the PCs scores across 120 Kentucky counties Pre- and Post- the expansion was analyzed by OLS (Table 27). The regression coefficients show that there is a positive association between PC2 (poverty/low income, unemployment, lack of medical professionals and facilities, rurality, low population density, and older age) county level T2DM-PH rates in Kentucky. The regression slopes for PC1 did not significantly differ between Pre-ACA $(B=0.024$, $\mathrm{SE}=0.313, \mathrm{p}=0.639)$ and Post- $\mathrm{ACA}(\mathrm{B}=0.183, \mathrm{SE}=0.218, \mathrm{p}=0.218)$ with $\mathrm{p}=0.67$ Similarly, the regression slopes for PC2 did not significantly differ between Pre-ACA $(B=$ 0.972, $\mathrm{SE}=0.313, \mathrm{p}=0.002)$ and Post- $\mathrm{ACA}(\mathrm{B}=1.01, \mathrm{SE}=0.218, \mathrm{p}=0.00)$ with $\mathrm{p}=0.72$.

The variance of county T2DM-PH rates reduced from Pre-ACA $\left(\sigma^{2}=3.341^{2}=\right.$ 11.162) to Post-ACA $\left(\sigma^{2}=2.334^{2}=5.448\right)$ (Figure 7$)$. The dispersion of county T2DM- 
$\mathrm{PH}$ rates around the regression line Pre-ACA was greater (with three outlier counties, Green, Lisle, and Breathitt) than Post-ACA T2DM-PH. The dispersion of county T2DM$\mathrm{PH}$ rates around the regression line decreased Post-ACA implementation and the three outlier counties (Green, Lisle, and Breathitt) lie much closer to the regression line with other counties' T2DM-PH rates, and are no longer outliers (Figure 8).

The positive coefficient (slope) indicates that as the value of the PC2 scores Preand Post- expansion increase, the county T2DM-PH rates also increase. The scaled slope (B) indicates the degree to which the T2DM-PH rate changes with a one-unit change in PC2 Pre-ACA (B=0.972, SE=0313, $\mathrm{p}=0.002)$ and Post- $\mathrm{ACA}(\mathrm{B}=1.01, \mathrm{SE}=0.218$, $\mathrm{p}=0.001)$.

An increase in the county PC2 score Pre-ACA was significantly associated with increased rates of T2DM-PH $(\mathrm{p}=0.002)$ (Table 27). That is, a one standard deviation increase in PC2 increased the rate of Pre-ACA T2DM-PH from 10.5 cases to 11.53 cases per 1000. Conversely, for every one standard deviation decrease in PC2, the T2DM-PH rate would decrease by 0.972 cases per 1000 .

Similarly, an increase in county PC2 score Post-ACA was significantly associated with increased rates of T2DM-PH $(\mathrm{p}=0.001)$ (Table 27). A one standard deviation increase in PC2 increased the rate of T2DM-PH from 10.1 cases to 11.1 cases per 1000. Conversely, every one standard deviation decrease in PC2 would decrease the T2DM-PH rate to 9 cases per 1000. In contrast, county PC1 value was not significantly associated with T2DM-PH rate Pre ACA $(\mathrm{p}=0.403)$ or Post ACA $(\mathrm{p}=0.639)($ Table 27$)$. 
Table 27: Principal components Predictors of T2DM-PH Pre and Post ACA

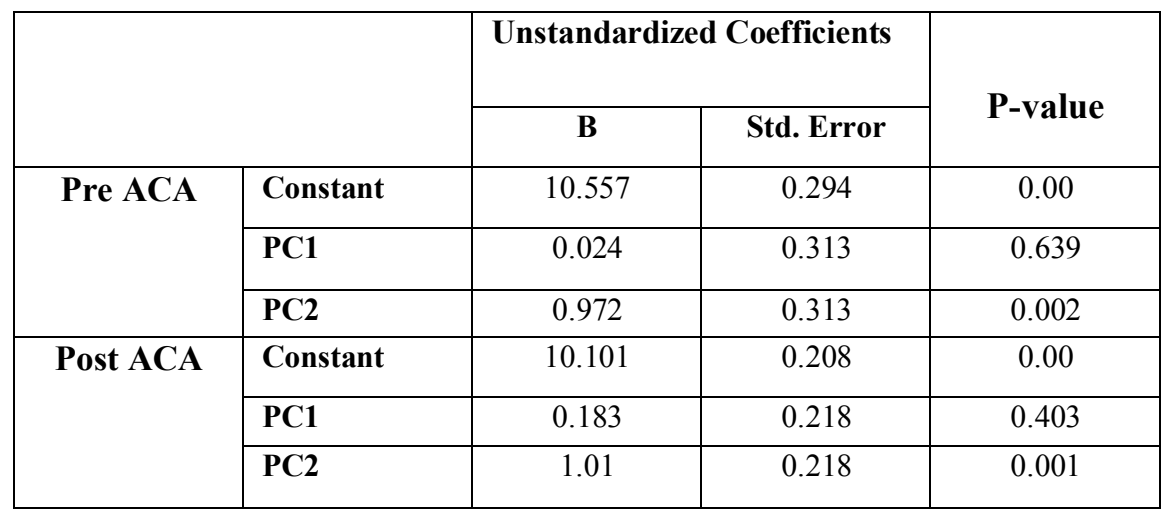

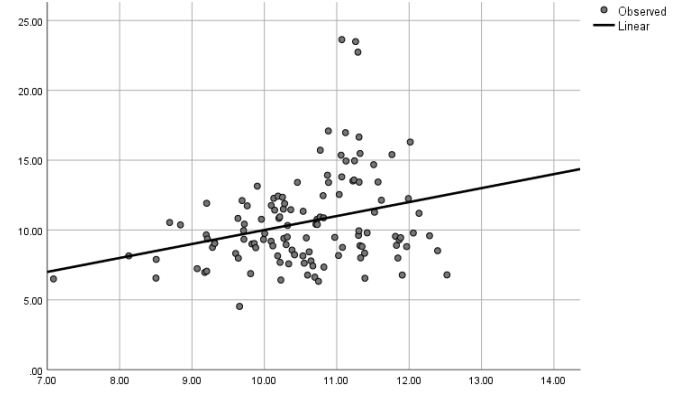

(a)

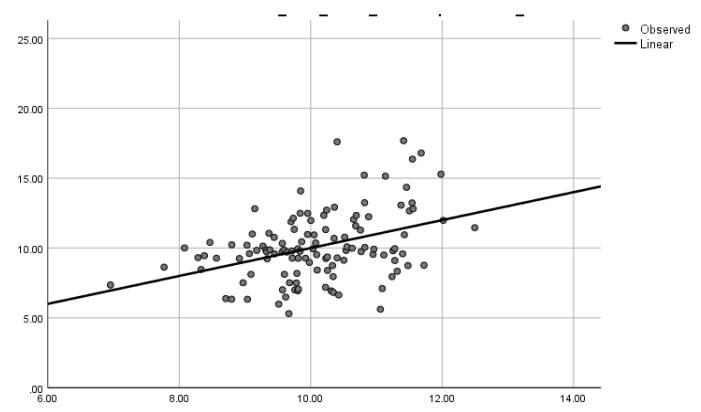

(b)

Figure 7: The dispersion of county T2DM-PH rates Pre-ACA (a) and Post-ACA (b) around the regression line.

\section{Summary of findings:}

The results of four statistical analyses of T2DM-PH in Kentucky discussed in this chapter show that there was a significant decrease in T2DM-PH rates Post-ACA Medicaid expansion by approximately $8.38 \%(\mathrm{p}=0.001)$. Moreover, the study also showed that the significant clusters of high T2DM-PH rates Pre- and Post-ACA were in the southeast region of Kentucky, the poorest counties in the state. The exception is Green County, which 
is in south-central Kentucky. Notably, Green County is one of the 3 counties that had the greatest reduction in uninsured rate. Table 28 lists key findings of the statistical analyses employed.

Table 28: Highlight on the study's results

\begin{tabular}{|c|c|c|c|}
\hline \multirow[t]{2}{*}{ Method } & \multicolumn{3}{|c|}{ Result } \\
\hline & Pre-ACA & Post-ACA & Sig. \\
\hline Descriptive & $54 \%$ of overall T2DM-PH & $46 \%$ of overall T2DM-PH & $\begin{array}{l}8.38 \% \\
\text { decrease } \\
(p=001) \\
\end{array}$ \\
\hline Cluster Analysis & $\begin{array}{l}\text { High T2DM-PH rate } \\
\text { counties significantly cluster } \\
\text { around each other in } \\
\text { southeast region of the state }\end{array}$ & $\begin{array}{l}\text { High T2DM-PH rate } \\
\text { counties significantly } \\
\text { cluster around each other } \\
\text { in southeast region of the } \\
\text { state }\end{array}$ & $\begin{array}{l}\text { Counties } \\
\text { had } \\
\text {-Positive z- } \\
\text { core, } \\
\text {-Positive } \\
\text { Moran's } \\
\text { Index } \\
\text { values } \\
\text { - p-value } \\
<0.05\end{array}$ \\
\hline $\begin{array}{c}\text { Principal } \\
\text { Component } \\
\text { Analysis (PCA) }\end{array}$ & $\begin{array}{l}\text { Two PCs were generated that } \\
\text { explain more than } 75.5 \% \text { of } \\
\text { the variation in county } \\
\text { socioeconomic factors. }\end{array}$ & $\begin{array}{l}\text { Two PCs were generated } \\
\text { that explain more than } 76 \% \\
\text { of the variation in county } \\
\text { socioeconomic factors }\end{array}$ & \\
\hline $\begin{array}{l}\text { Ordinary Least } \\
\text { Squares (OLS) }\end{array}$ & $\begin{array}{l}\text { Significant positive } \\
\text { association between high } \\
\text { T2DM-PH rate and high } \\
\text { PC2 scores }\end{array}$ & $\begin{array}{l}\text { Significant association } \\
\text { between high T2DM-PH } \\
\text { rate and high PC2 scores }\end{array}$ & $\begin{array}{l}\text { Pre-ACA } \\
(p=0.02) \\
\text { Post-ACA } \\
(p=0.001)\end{array}$ \\
\hline
\end{tabular}




\section{CHAPTER V}

DISCUSSION

The aim of the present study was to compare the impact of Medicaid expansion on geographic patterns of T2DM-PH rates across Kentucky counties. The study also aimed to determine significant socioeconomic characteristics that predict the rates of T2DM-PH across counties in Kentucky before and after Medicaid expansion. This study found a decrease in T2DM-PH rates after the implementation of the Medicaid expansion. The decrease across Kentucky counties was not randomly distributed. High T2DM-PH rate counties significantly cluster in the southeast region Pre- and Post-Medicaid expansion. Therefore, the null hypothesis was rejected. Additionally, analyses mapped two socioeconomic PCs Pre-ACA and two socioeconomic PCs Post-ACA that explain more than 75 percent of the variation in county socioeconomic factors in Kentucky. Linear regression was used to analyze the association between the socioeconomic PCs Pre- and Post-ACA and the counties' T2DM-PH rates. The regression analysis showed that PC2 Preand Post-ACA significantly predict the county T2DM-PH rate. In addition, county-level variance in T2DM-PH rates declined after the Medicaid expansion. This reduction is due to a significant decrease in the county uninsured rate (Table 14). Notably, Green, Breathitt, and Leslie counties were outliers with high uninsured rates and high T2DM-PH rate PreACA (Figure 7, Table 14). These three counties had a marked decline in T2DM-PH rates and uninsured rate after the Medicaid expansion (Figure 7, Table 14). Thus, the ACA substantially changed T2DM-PH in counties that had a high uninsured rate Pre-ACA. 
The results support the alternative hypotheses that T2DM-PH variation in Kentucky is not random, and found clusters of high T2DMP-PH rates in the southeast Pre and Post expansion, which highlighted the importance of county level economic characteristics. This study's outcomes support programs such as the Kentucky Helping to Engage and Achieve Long Term Health (KY HEALTH) Medicaid 1115 Waiver, which was approved by the Centers for Medicare \& Medicaid Services (CMS) in January 2018. It aims to modify the traditional Medicaid program to improve health behaviors, health outcomes, and socioeconomic outcomes in the waiver-eligible population through several innovations (L. A. Blewett, C. Planalp, \& G. Alarcon, 2018).

\section{Variation in T2DM-PH in Kentucky}

Analysis of hospital discharge data from KID, in this study, found 8.39 percent reduction in T2DM-PH rates among adults after the implementation of the Medicaid expansion in Kentucky. In 2019, Wen et al. reported a significant reduction in state level ACSC PH rates Post-ACA. Changes in the state level PH rates decreased from the Preexpansion period of 2009-2013 to the Post-expansion period of 2014-2015 (11.96 percent versus 7.80 percent) nationally (Wen et al., 2019). PH declines associated with Medicaid expansions were largely concentrated in chronic respiratory conditions, T2DM-related complications, and bacterial pneumonia (Wen et al., 2019). Another study in 2019 analyzed state level hospital discharge data for adults with T2DM in 2013-2014. From 2013 (PreACA) to 2014 (Post-ACA), Medicaid expansion was associated with small but significant decreases in PH proportions for adults with T2DM (difference between 2014 and 2013 was 0.17 percentage points in expansion and 0.37 percentage points in non-expansion states, 
$\mathrm{p}=0.04)$ (Mondesir et al., 2019). Similarly, this study's result supports the finding that Medicaid expansion helped decrease PH rates related to T2DM (Figure 1, Table 14), but analyses over a longer period showed changes greater in magnitude.

A general reduction in T2DM-PH rates was observed. Counties with a high T2DMPH rate were significantly clustered around each other with high positive z-scores, positive Moran's Index values and significant $\mathrm{p}$ value during both time periods (Table 19). There were 14 and 12 counties with high T2DM-PH rates clusters Pre- and Post-ACA, respectively. The significant high cluster counties on PC2 during both timeframes were in the southeast region, including Letcher, Bell, Leslie, Perry, Knott, and Magoffin counties. Spatial clustering of counties with similar rates of $\mathrm{PH}$ in southern regions of Texas such as Zapata, Starr, Cameron, and Willacy showed a similar pattern (Nkem, 2014). Significant clusters of high T2DM-PH in the current study were in low-income counties that are largely rural, have weak job markets, and older median age populations.

\section{Association of T2DM-PH with counties' socioeconomics characteristics}

The complexity of the high dimensional socioeconomic data was dealt with PCA. PCA was used to transform high dimensional socioeconomic factors into fewer dimensions. In this study, two PCs were generated for each periods (before and after Medicaid expansion) that explained more than 75 percent of the variance in AHRF socioeconomic indicators, which consisted of 12 county level socioeconomic variables. PCs scores were mapped to visualize socioeconomic disparities across counties in 20102013 VS. 2014-2017. Linear regression analysis was used to analyze the predictive ability of PCs for T2DM-PH rates across Kentucky counties Pre-ACA and Post-ACA. Counties 
with that PC2 (economic PC) high scores were significantly associated with high T2DMPH rates across counties in Kentucky Pre and Post Medicaid expansion. High PC2 scores Pre- and Post-ACA indicated low income, high unemployment rate, high poverty rate, rurality, and older adults. All counties with high PC2 scores before and after the Medicaid expansion were located in the southeast region of Kentucky.

Uninsured: Insured individuals with T2DM were more likely than the uninsured to manage and control the progression of their condition, receive care in the correct setting, and less likely have to have a PH. Prior studies found that the percentage of uninsured Kentuckians has dramatically decreased since Kentucky implemented the ACA and expanded Medicaid (L. A. Blewett et al., 2018). The current study found that counties with a high PC2 score, that loaded with high uninsured rates, were significantly associated with counties that have high rates of T2DM-PH $(\mathrm{p}<0.05)$ Pre and Post ACA. This is due to a persistent weak economic profile in those counties before and after the ACA. Notably, ACA affected health coverage, and not economic expansion.

Poverty: Poverty is a well-recognized contributor to medical conditions and PH (Sraders, 2018). Several investigations have analyzed poverty rate and income level effects on healthcare access. In prior studies, low income individuals are more likely to face greater barriers to medical access, resulting in a higher likelihood of PH (Rosenbaum et al., 2017). In Kentucky, 34 percent of the population was below 200\% FPL (Rosenbaum et al., 2017). Counties in different regions have different poverty rates, but the majority of counties with high poverty rates in Kentucky are concentrated in the southeastern region of the State 
(Rosenbaum et al., 2017). Poverty rates in southeastern counties (i.e., Wolfe, Harlan, Letcher, Bell, Leslie, Perry, Knott, Magoffin, Breathitt, Owsley, Clay, and Pike) ranged from 30-40 percent before and after the Medicaid expansion. Similar to the previous study, the current study found that counties with high poverty rates had high scores on PC2 (county socioeconomic profiles) Pre- and Post-ACA. Notably, there were counties, that had high rates of T2DM-PH ( $<<0.05)$ (Tables 25 and 26).

Income: The majority of the prior studies found that the level of income inequality (i.e. variation in median household income in a geographic area and family-level income) was associated with poorer health outcomes (J. Kim et al., 2019). Income is a proxy for education level, barriers to accessing primary care and health insurance (Heintzman et al., 2017). Low income neighborhoods were strongly associated with high rates of PH in one study (Bettenhausen et al., 2017). Consistent with previous studies, the current study found that the low income per capita, high unemployment rate, and low median household income in PC2 county economic profiles Pre- and Post-ACA were significantly associated with counties that had high rates of T2DM-PH $(\mathrm{p}<0.05)$.

Rurality and urbanization: Minc et al. (2019) created maps to illustrate T2DM-PH in Virginia State from 2011 to 2016. Patients admitted with T2DM in a rural area had a significantly higher risk of hospitalization for amputation in western regions of Virginia where 97 percent of the population is rural (Minc et al., 2019). Rural residence was associated with a 40 percent higher PH rate, including T2DM-PH, compared to urban residence (Johnston et al., 2019). Similarly, this study found that counties with low levels 
of urbanization scored high in PC2 economic profiles Pre- and Post-ACA. High PC2 scores in both periods significantly associated with counties that had a high T2DM-PH rate $(\mathrm{p}<0.05)$.

Kentucky Cabinet for Health and Family Services reported that rural counties are growing more slowly and had higher rates of poverty and low income compared to urban counties in the state (Commonwealth of Kentucky, 2015). It was estimated that $24 \%$ of rural county populations in Kentucky live below the FPL (Myint et al., 2019). The ten counties with higher poverty rates are all rural counties and located in the southeast region of the State led by Wolfe County with a poverty rate of 42.2 percent (Figure 8).

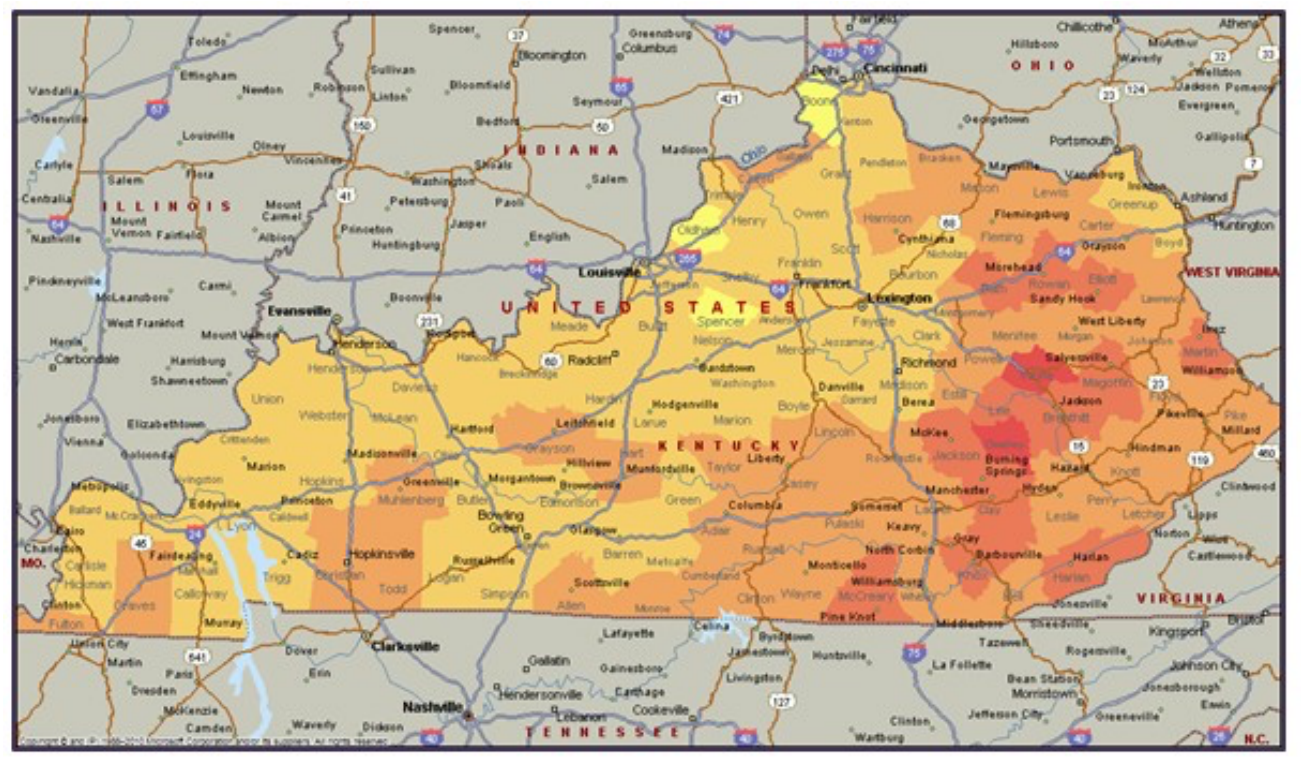

40 to 46 percent 30 to 39 percent 20 to 29 percent 10 to 19 percent 5 to 9 percent

Figure 8: Counties by percent living below the poverty level 
Kentuckians who live in southeast rural areas have poorer health outcomes than their urban counterparts do, as illustrated in the cluster of higher T2DM-PH rates in southeast Kentucky (Figure 9) (Commonwealth of Kentucky, 2015). Lower T2DM-PH rates were reported in urban counties in the north region of Kentucky such as Oldham, Scott, Spencer, and Henry. Counties that are metropolitan have better economic metrics than those in the southeast region of the State (Commonwealth of Kentucky, 2015).

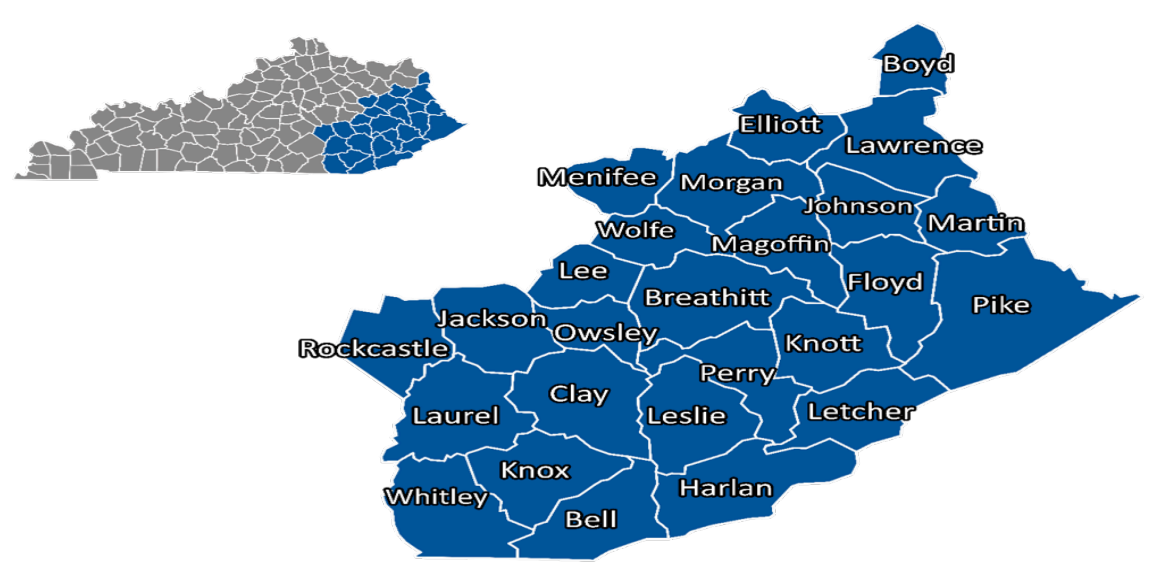

Figure 9: Counties with poorer health outcomes

Although T2DM-PH rates declined after ACA implementation, the gap in T2DM$\mathrm{PH}$ rates between rural and urban counties persists. Policymakers need to focus on the economic inequality in Kentucky because the state has one of the highest income inequalities in the nation (Baumann \& Bailey, 2016). Since the 1970s, income inequality in Kentucky between urban counties and rural counties has been increasing (Minier, Hoyt, \& Childress, 2019). A recent analysis indicated that the average income of the top one percent of Kentuckians who live in the northern region is 18 times greater than the average 
income of the State's residents (Minier et al., 2019). The Economic Policy Institute reported that the top one percent income in Kentucky has grown 23.2 percent while the remainder of the population saw income grow only 7.2 percent (Minier et al., 2019). Income disparities in Kentucky magnify the problem of wealth distribution and poverty in the State. This economic situation places the rural population at a greater economic disadvantage, and this negatively affects many other dimensions, including health outcomes. Numerous studies indicate that living in poverty places adults at risk for a myriad diseases, including T2DM. Poverty is a chronic stress that adversely affects health. The strain of being poor and living in inadequate housing, or not having any housing at all, can spike levels of cortisol, which can cause a wide range of negative side effects, such as high blood sugar levels (Anekwe \& Rahkovsky, 2014). Low-income households tend to eat less nutritious diets than other households. On average, they do not meet Federal recommendations for consumption of fruit, vegetables, whole grains, and low-fat dairy products, and they consume fewer servings of these nutritious foods than other households (Anekwe \& Rahkovsky, 2014). Malnutrition leads to immune dysfunction, which can directly drive pathological processes and greater susceptibility to PH (Becker et al., 2020).

Successful T2DM management includes daily blood glucose monitoring, record keeping, medication, and lifestyle modifications (diet, exercise) (Becker et al., 2020). T2DM is a complex chronic condition that requires daily care, but patients with T2DM in poor counties have difficulty with self-management and compliance because of limited access to healthcare resources, competing economic (e.g., buy food or medicine) demands and other social, economic and cultural barriers directly related to poverty status (Lambrinou, Hansen, \& Beulens, 2019). Failure in medication adherence/compliance and 
behavior self-management (diet, exercise) among T2DM patients results in adverse health outcomes (T2DM-PH).

\section{The economic implications of T2DM-PH in Kentucky}

The latest health policy enacted to improve access to outpatient healthcare among poor populations in Kentucky is the Medicaid expansion. The present study found a significant 8.3 percent decrease in the number of T2DM-PH cases Post ACA $(\mathrm{P}=0.02)$. Despite significant reductions in T2DM-PH rates in Kentucky, the present study also found a significant increase in the average cost per hospitalization Post-ACA. Adjusting all T2DM-PH costs to 2020 dollars, the average cost per each T2DM-PH significantly increased from $\$ 30,200$ Pre-ACA to $\$ 39,400$ Post-ACA $(p=0.001)$. The underlying factors that increased the cost of T2DM-PH Post-ACA may result from the increased in cost per patient related to length of stay (days). It was found that the average length of stay per hospitalization significantly increased from 4.6 days Pre-ACA to 6 days Post-ACA (p $=0.02$ ). According to the American Diabetes Association's (ADA), T2DM is the most expensive chronic disease in the U.S. The biggest contributors to T2DM costs are the use of hospital inpatient services (American Diabetes Association, 2017). ADA published a national study in 2018 on the economic costs of T2DM in the U.S. in 2017, and reported the direct medical costs, including inpatient care of T2DM, increased by $26 \%$ from 2012 to 2017 (Einarson, Acs, Ludwig, \& Panton, 2018). The (Einarson et al., 2018). The literature and the current study highlight the substantial financial burden that T2DM-PH imposes on the healthcare system. Therefore, reducing T2DM-PH disparities in Kentucky is an important goal to improve healthcare system efficiency. Kentucky needs to increase 
its efforts to overcome rural-urban T2DM-PH disparities, a problem deeply rooted in economic, social, and geographic factors. This complex system of influences makes finding solutions difficult, especially for rural communities.

\section{Intervention approach for T2DM-PH in Kentucky}

In Kentucky, Medicaid expansion and other interventions have been promoted to address chronic conditions, including T2DM. Recent interventions that target T2DM-PH in the State include the National Diabetes Prevention Program (DPP) and Diabetes SelfManagement Education and Support (DSMES) (Minier et al., 2019). These structured programs are population-based public health initiatives that are aimed to improve T2DM self-management education and support. Their efforts include promoting awareness of T2DM through providing continuing education about T2DM to healthcare professionals and patients (Minier et al., 2019). Despite the abundance of evidence supporting the benefits of DSMES, it continues to be a underutilized (Minier et al., 2019).

At least $45 \%$ of patients with T2DM fail to achieve adequate glycemic control (HbA1C $<7$ percent) (K. Kim et al., 2019). Hemoglobin A1C (HbA1c) indicates the average blood sugar for the previous two to three months (K. Kim et al., 2019). ADA recommends $\mathrm{T} 2 \mathrm{DM}$ patients to maintain an average $\mathrm{HbA} 1 \mathrm{C}$ of 6.5 percent to 7 percent (Smetana, Nathan, Dugdale, \& Burns, 2019). Failing to maintain the recommended level may result in T2DM complications, increase the risk of the T2DM-PH, and increase the economic burden of the disease (Smetana et al., 2019). Patients with a primary diagnosis of uncontrolled short- and long-term T2DM complications had significantly higher HbA1c than those with a controlled T2DM ( $\mathrm{P}=0.003)$ (Liang, Chang, \& Lin, 2019). In the present 
study, the majority of the T2DM-PH before and after the expansion had a primary diagnosis of uncontrolled short and long term T2DM complications (i.e. hyperglycemia, hypoglycemia, ketoacidosis, and microvascular complications). Eighty three percent of patients Pre-ACA and seventy six percent of patients Post-ACA T2DM-PH had uncontrolled T2DM complications as a primary diagnosis. Therefore, intervention to maintain the control of $\mathrm{HbA} 1 \mathrm{c}$ below 7 percent level is extremely important.

Two major contributing factors lead to uncontrolled glycemia (T2DM): (1) poor patient adherence and compliance and (2) quality of care (Polonsky \& Henry, 2016). Poor medication adherence/compliance in T2DM is very common and is associated with inadequate glycemic control. In addition, poor patient adherence/compliance leads to increased morbidity, costs of outpatient care, and the risk of T2DM-PH. Poor medication adherence/compliance is linked to several factors, such as, patient perception of medication and self-management (Benson, Okeke, \& Okeke, 2017).

The second contributing factor that leads to uncontrolled glycemia (T2DM) is the quality of the provided care. Successful T2DM care requires an integrated organized care approach. It is important to have the involvement of a coordinated team of healthcare providers working in an environment where patient-centered high-quality care is a priority (Thom \& Bodenheimer, 2017). In rural populations with limited physical access to health care, telemedicine is an approach with a growing evidence of effectiveness, particularly with regard to glycemic control as measured by HbAlc (Thom \& Bodenheimer, 2017). The use of telecommunications to facilitate remote delivery of health-related services and clinical information can be an efficient and effective tool to ensure the quality of the provided care regardless of patients' location (Wager, Lee, \& Glaser, 2017). Also, 
providers must be educated and aware of the appropriate interactive strategies that consider patients' culture in communication (Kline et al., 2016).

Health policy makers in Kentucky should focus on strategies that target patient adherence/compliance, and quality of care provided. Solutions to this problem would require innovative behavioral approaches. Adherence/compliance to medications dose and frequency, and outpatient care quality can improve patient outcomes and consequently reduce the cost of care. Several researchers found that provision of financial incentives is a promising intervention for improving service provided as well as the adherence/compliance in patients. Several studies suggest that incentive-based medication adherence interventions can be effective (Noordraven et al., 2017). Financial incentives shared by healthcare providers and patients can assist with reducing in T2DM-PH rates in Kentucky compared with paying only the physician (Figure 10). T2DM patients whose physicians receive financial incentives for quality of care tended to improve quality of care. However, this was not enough to change their patients' HbAlc levels (Fichera, Banks, Siciliani, Sutton, \& Organization, 2018). Patients with T2DM and their providers receive incentives for each period as long as the patients maintain $\mathrm{HbAlc}$ levels below 7 percent (Figure 10). Financial incentives shared by both physicians and patients can be implemented in southeast Kentucky where the high T2DM-PH rate clusters exist. Successful reduction in T2DM-PH rates in the southeast region have the potential to markedly reduce costs associated with T2DM-PH. Further investigation is needed to evaluate this strategy and estimate the relative cost-effectiveness of such an intervention. 
Figure 10: Conceptual model of T2DM-PH intervention in Kentucky

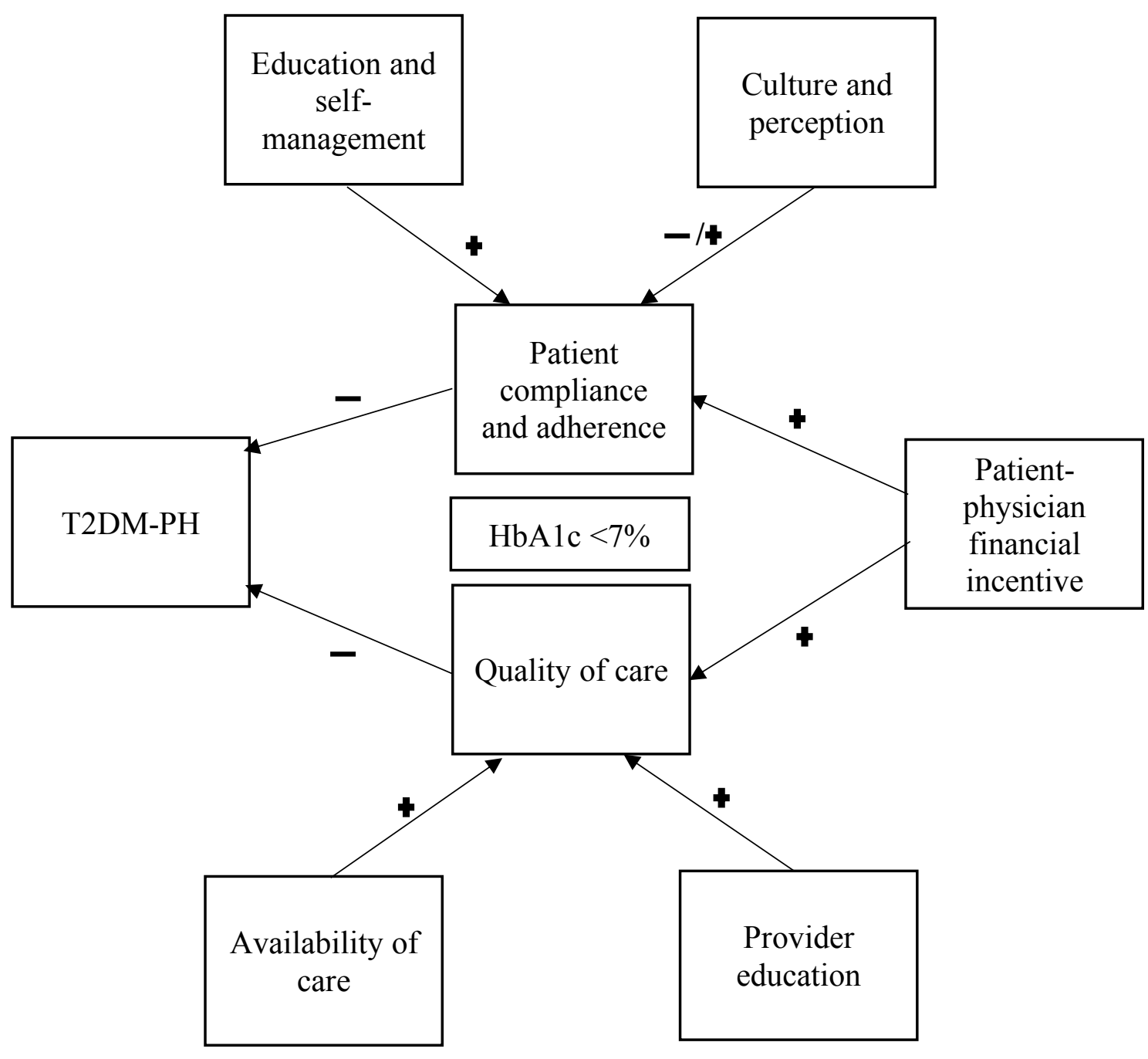

\section{Study Limitations}

Limitations of the present study include four major areas:

1. The use of secondary data to analyze the geographic variation in T2DM-PH.

2. The effect observed is an association, and not directly causal. Therefore, effects cannot be causally attributed to explanatory factors, because this is cross-sectional observational data. 
3. The data used were de-identified and do not provide insights into the frequency of hospitalizations per patient.

4. Variation in reported data quality may exist, but this could not be analyzed. The quality of information reported to KID may vary, based on each reporting hospital quality controls, even with the KID process of automated auditing and verification.

\section{Conclusion}

This study analyzed variation in T2DM-PH in Kentucky and found that Medicaid expansion was associated with reduced T2DM-PH rates at the county level in Kentucky. Significant spatial clusters were found Pre- and Post-ACA, indicating clusters of counties with high T2DM-PH rates surrounded with counties with high T2DM-PH rates in the southeast region of Kentucky. Extremely disadvantaged rural counties in southeast Kentucky scored highest on the socioeconomic deprivation profile component (PC2) and were significantly associated with high T2DM-PH rates $(\mathrm{p}<0.05)$. These findings have important public health implications for health policy and economic disparities, calling for ways to enable success of lifestyle intervention programs. A conceptual model of T2DMPH intervention was derived that suggests a patient-physician financial incentive approach that can be implemented in southeast Kentucky where the high-high T2DM-PH rates cluster exist. Reducing the number of T2DM-PH in these counties will contribute to both increased quality of care and reduced health care expenditures. Reducing T2DM-PH represents a substantial "win" in restraining costs as well as enhancing T2DM patients' quality of life. Finally, this study identified the need for further investigation into the costs 
associated with each preventable T2DM hospitalization to determine the economic impact of Medicaid expansion among T2DM-PH in Kentucky. 


\section{REFERENCES}

Adepoju, O. E., Preston, M. A., \& Gonzales, G. J. A. J. o. P. H. (2015). Health care disparities in the post-Affordable Care Act era. 105(S5), S665-S667.

Agency for Health care Research and Quality. (2018). Prevention Quality Indicators Technical Specifications Updates - Version v2018 and v2018.0.1 (ICD 10CM/PCS), June 2018. Retrieved from https://www.qualityindicators.ahrq.gov/Modules/PQI_TechSpec_ICD10_v2018.a $\underline{\mathrm{spx}}$

Agency for Healthcare Research and Quality Indicators. (2002). Guide to Prevention Quality Indicators: Hospital Admission for Ambulatory Care Sensitive Conditions, . Retrieved from https://www.ahrq.gov/downloads/pub/ahrqqi/pqiguide.pdf

AHRQ Quality Indicators. (2016). Prevention Quality Indicator Retrieved from https://www.qualityindicators.ahrq.gov/Modules/pqi resources.aspx

America's Health Rankings. (2018). Preventable Hospitalization in Kentucky in 2018. Retrieved from https://www.americashealthrankings.org/explore/senior/measure/preventable hos pitalizations_sr/state/KY

American Diabetes Association. (2017). The Burden of Diabetes in Kentucky. Retrieved from http://main.diabetes.org/dorg/PDFs/Advocacy/burden-ofdiabetes/kentucky.pdf

Anekwe, T. D., \& Rahkovsky, I. (2014). The association between food prices and the blood glucose level of US adults with type 2 diabetes. Am J Public Health, 104(4), 678-685. doi:10.2105/AJPH.2013.301661

Batavia, A. I., Beaulaurier, R. L. J. J. S., \& Welfare, S. (2001). The financial vulnerability of people with disabilities: Assessing poverty risks. 28, 139.

Baumann, A., \& Bailey, J. (2016). THE STATE OF WORKING KENTUCKY -2016.

Becker, J., Emmert-Fees, K. M. F., Greiner, G. G., Rathmann, W., Thorand, B., Peters, A., ... Schwettmann, L. (2020). Associations between self-management behavior and sociodemographic and disease-related characteristics in elderly people with type 2 diabetes - New results from the population-based KORA studies in Germany. Prim Care Diabetes. doi:10.1016/j.pcd.2020.01.004

Benson, E.-o. N., Okeke, N. T., \& Okeke, C. B. J. J. N. P. s. (2017). Factors that Influence Insulin Adherence in Self-Administration and Actions that Could Improve it. J Nursing Palliat serv 1: 106. 1(1), 16-22.

Bettenhausen, J. L., Colvin, J. D., Berry, J. G., Puls, H. T., Markham, J. L., Plencner, L. M., ... Hall, M. (2017). Association of Income Inequality With Pediatric Hospitalizations for Ambulatory Care-Sensitive Conditions. JAMA Pediatr, 171(6), e170322. doi:10.1001/jamapediatrics.2017.0322 
Blewett, L. A., Planalp, C., \& Alarcon, G. (2018). Affordable Care Act Impact in Kentucky: Increasing Access, Reducing Disparities. Am J Public Health, 108(7), 924-929. doi:10.2105/AJPH.2018.304413

Blewett, L. A., Planalp, C., \& Alarcon, G. J. A. j. o. p. h. (2018). Affordable Care Act Impact in Kentucky: Increasing Access, Reducing Disparities. 108(7), 924-929.

Bocour, A., \& Tria, M. (2016). Preventable Hospitalization Rates and Neighborhood Poverty among New York City Residents, 2008-2013. J Urban Health, 93(6), 974-983. doi:10.1007/s11524-016-0090-5

Boissy, R., Ahmed, A., Janto, B., Earl, J., Hall, B. G., Hogg, J. S., . . Hu, F. Z. (2011). Comparative supragenomic analyses among the pathogens Staphylococcus aureus, Streptococcus pneumoniae, and Haemophilus influenzae using a modification of the finite supragenome model. BMC Genomics, 12, 187. doi:10.1186/1471-2164-12-187

Centers for Disease Control and Prevention. (2016). Kentucky Leading Causes of Death, . Retrieved from https://www.cdc.gov/nchs/pressroom/states/kentucky/kentucky.htm

Chen, P.-C., Tsai, C.-Y., Woung, L.-C., \& Lee, Y.-C. J. I. j. f. e. i. h. (2015). Socioeconomic disparities in preventable hospitalization among adults with diabetes in Taiwan: a multilevel modelling approach. 14(1), 31.

Chen, P. C., Tsai, C. Y., Woung, L. C., \& Lee, Y. C. (2015). Socioeconomic disparities in preventable hospitalization among adults with diabetes in Taiwan: a multilevel modelling approach. Int J Equity Health, 14, 31. doi:10.1186/s12939-015-0160-4

Cho, H. E., Wang, L., Chen, J. S., Liu, M., Kuo, C. F., \& Chung, K. C. (2019). Investigating the causal effect of socioeconomic status on quality of care under a universal health insurance system - a marginal structural model approach. BMC Health Serv Res, 19(1), 987. doi:10.1186/s12913-019-4793-7

Commonwealth of Kentucky. (2015). Kentucky Diabetes Report. Retrieved from https://chfs.ky.gov/agencies/dph/Documents/2015DiabetesReportFinal.pdf

Daly, M. R., Mellor, J. M., \& Millones, M. (2018). Do Avoidable Hospitalization Rates among Older Adults Differ by Geographic Access to Primary Care Physicians? Health Serv Res, 53 Suppl 1, 3245-3264. doi:10.1111/1475-6773.12736

Degerlund Maldi, K., San Sebastian, M., Gustafsson, P. E., \& Jonsson, F. (2019). Widespread and widely widening? Examining absolute socioeconomic health inequalities in northern Sweden across twelve health indicators. Int J Equity Health, 18(1), 197. doi:10.1186/s12939-019-1100-5

Einarson, T. R., Acs, A., Ludwig, C., \& Panton, U. H. J. V. i. H. (2018). Economic burden of cardiovascular disease in type 2 diabetes: a systematic review. 21(7), 881-890.

Falster, M. O., Jorm, L. R., Douglas, K. A., Blyth, F. M., Elliott, R. F., \& Leyland, A. H. (2015). Sociodemographic and health characteristics, rather than primary care supply, are major drivers of geographic variation in preventable hospitalizations in Australia. Med Care, 53(5), 436-445. doi:10.1097/MLR.0000000000000342

Feng, C., Paasche-Orlow, M. K., Kressin, N. R., Rosen, J. E., Lopez, L., Kim, E. J., . . . Hanchate, A. D. (2018). Disparities in Potentially Preventable Hospitalizations: Near-National Estimates for Hispanics. Health Serv Res, 53(3), 1349-1372. doi:10.1111/1475-6773.12694 
Fichera, E., Banks, J., Siciliani, L., Sutton, M. J. J. o. E. B., \& Organization. (2018). Does patient health behaviour respond to doctor effort? , 156, 225-251.

Fisher, M. A., \& Ma, Z. J. A. J. M. C. (2015). Medicaid-insured and uninsured were more likely to have diabetes emergency/urgent admissions. 21(5), e312-e319.

Foundation, K. F. (2016). Key facts about the uninsured population.

French, M. T., Homer, J., Gumus, G., \& Hickling, L. (2016). Key Provisions of the Patient Protection and Affordable Care Act (ACA): A Systematic Review and Presentation of Early Research Findings. Health Serv Res, 51(5), 1735-1771. doi:10.1111/1475-6773.12511

Hakeem, F. B., Howard, D. L., Carey, T. S., Taylor, Y. J. J. J. o. H. D. R., \& Practice. (2009). Differential effects of race and poverty on ambulatory care sensitive conditions. 3(1), 7.

Heintzman, J., Bailey, S. R., DeVoe, J., Cowburn, S., Kapka, T., Duong, T.-V., . . . disparities, e. h. (2017). In low-income Latino patients, post-Affordable Care Act Insurance disparities may be reduced even more than broader national estimates: evidence from Oregon. 4(3), 329-336.

Helmer, D. A., Rowneki, M., Feng, X., Tseng, C. L., Rose, D., Soroka, O., . . . Sambamoorthi, U. (2018). State-Level Variability in Veteran Reliance on Veterans Health Administration and Potentially Preventable Hospitalizations: A Geospatial Analysis. Inquiry, 55, 46958018756216. doi: $10.1177 / 0046958018756216$

Johnston, K. J., Wen, H., \& Joynt Maddox, K. E. (2019). Lack Of Access To Specialists Associated With Mortality And Preventable Hospitalizations Of Rural Medicare Beneficiaries. Health Aff (Millwood), 38(12), 1993-2002. doi:10.1377/hlthaff.2019.00838

Kentucky Cabinet for Health and Family Services. (2017). 2017 Kentucky Diabetes Report. Retrieved from http://chfs.ky.gov/dph/info/dpqi/cd/diabetes.htm

Kentucky Department for Public Health. (2017). Kentucky State Health Improvement Plan 2017-2022. Retrieved from https://chfs.ky.gov/agencies/dph/Documents/StateHealthImprovementPlan201720 22.pdf

Kentucky Public Health. (2018). 2018 KENTUCKY DIABETES FACT SHEET. Retrieved from https://madisoncountyhealthdept.org/Documents/Community/2018KYDiabetesFa ctSheet.pdf

Kim, H., Helmer, D. A., Zhao, Z., \& Boockvar, K. J. T. A. j. o. m. c. (2011). Potentially preventable hospitalizations among older adults with diabetes. 17(11), e419-426.

Kim, J., Kang, H. Y., Lee, K. S., Min, S., \& Shin, E. (2019). A Spatial Analysis of Preventable Hospitalization for Ambulatory Care Sensitive Conditions and Regional Characteristics in South Korea. Asia Pac J Public Health, 31(5), 422432. doi:10.1177/1010539519858452

Kim, K., Unni, S., McAdam-Marx, C., Thomas, S. M., Sterling, K. L., Olsen, C. J., . . . pharmacy, s. (2019). Influence of Treatment Intensification on A1c in Patients with Suboptimally Controlled Type 2 Diabetes After 2 Oral Antidiabetic Agents. 25(3), 314-322. 
Kline, K. N., Montealegre, J. R., Rustveld, L. O., Glover, T. L., Chauca, G., Reed, B. C., \& Jibaja-Weiss, M. L. J. J. o. h. c. (2016). Incorporating cultural sensitivity into interactive entertainment-education for diabetes self-management designed for Hispanic audiences. 21(6), 658-668.

Kuo, Y. F., Chen, N. W., Baillargeon, J., Raji, M. A., \& Goodwin, J. S. (2015). Potentially Preventable Hospitalizations in Medicare Patients With Diabetes: A Comparison of Primary Care Provided by Nurse Practitioners Versus Physicians. Med Care, 53(9), 776-783. doi:10.1097/MLR.0000000000000406

Lambrinou, E., Hansen, T. B., \& Beulens, J. W. (2019). Lifestyle factors, selfmanagement and patient empowerment in diabetes care. Eur J Prev Cardiol, 26(2_suppl), 55-63. doi:10.1177/2047487319885455

Liang, Y.-W., Chang, H.-F., \& Lin, Y.-H. J. B. h. s. r. (2019). Effects of healthinformation-based diabetes shared care program participation on preventable hospitalizations in Taiwan. 19(1), 890.

Mahal, A. R., Chavez, J., Yang, D. D., Kim, D. W., Cole, A. P., Hu, J. C., . . Mahal, B. A. (2019). Early Impact of the Affordable Care Act and Medicaid Expansion on Racial and Socioeconomic Disparities in Cancer Care. Am J Clin Oncol. doi:10.1097/COC.0000000000000588

Margolis, D. J., Hoffstad, O., Nafash, J., Leonard, C. E., Freeman, C. P., Hennessy, S., \& Wiebe, D. J. J. D. c. (2011). Location, location, location: geographic clustering of lower-extremity amputation among Medicare beneficiaries with diabetes. 34(11), 2363-2367.

Minc, S. D., Hendricks, B., Misra, R., Ren, Y., Thibault, D., Marone, L., \& Smith, G. S. (2019). Geographic variation in amputation rates among patients with diabetes and/or peripheral arterial disease in the rural state of West Virginia identifies areas for improved care. J Vasc Surg. doi:10.1016/j.jvs.2019.06.215

Minier, J., Hoyt, W. H., \& Childress, M. T. (2019). Kentucky Annual Economic Report 2019.

Mobley, L. R., Root, E., Anselin, L., Lozano-Gracia, N., \& Koschinsky, J. J. I. j. o. h. g. (2006). Spatial analysis of elderly access to primary care services. 5(1), 19.

Mondesir, F. L., Kilgore, M. L., Shelley, J. P., Levitan, E. B., Huang, L., Riggs, K. R., . . . Cherrington, A. L. (2019). Medicaid Expansion and Hospitalization for Ambulatory Care-Sensitive Conditions Among Nonelderly Adults With Diabetes. J Ambul Care Manage, 42(4), 312-320. doi:10.1097/JAC.0000000000000280

Myint, Z. W., O'Neal, R., Chen, Q., Huang, B., Vanderpool, R., \& Wang, P. (2019). Disparities in prostate cancer survival in Appalachian Kentucky: a populationbased study. Rural Remote Health, 19(2), 4989. doi:10.22605/RRH4989

Nkem, M. (2014). Population and community predictors of preventable hospitalizations in Texas. The University of Texas School of Public Health,

Noordraven, E. L., Wierdsma, A. I., Blanken, P., Bloemendaal, A. F., Staring, A. B., \& Mulder, C. L. J. T. L. P. (2017). Financial incentives for improving adherence to maintenance treatment in patients with psychotic disorders (Money for Medication): a multicentre, open-label, randomised controlled trial. 4(3), 199-207.

Peach, R. L., Yaliraki, S. N., Lefevre, D., \& Barahona, M. (2019). Data-driven unsupervised clustering of online learner behaviour. NPJ Sci Learn, 4, 14. doi:10.1038/s41539-019-0054-0 
Pezzin, L. E., Bogner, H. R., Kurichi, J. E., Kwong, P. L., Streim, J. E., Xie, D., . . Hennessy, S. (2018). Preventable hospitalizations, barriers to care, and disability. Medicine (Baltimore), 97(19), e0691. doi:10.1097/MD.0000000000010691

Plant, R. E. (2018). Principal components analysis.

Polonsky, W. H., \& Henry, R. R. (2016). Poor medication adherence in type 2 diabetes: recognizing the scope of the problem and its key contributors. Patient Prefer Adherence, 10, 1299-1307. doi:10.2147/PPA.S106821

Resources, H., \& Administration, S. (2014). Area Health Resources Files (AHRF).

Riddle, M. C., \& Herman, W. H. (2018). The cost of diabetes care-An elephant in the room. Diabetes Care, 41(5), 929-932. doi:10.2337/dci18-0012

Rizza, P., Bianco, A., Pavia, M., \& Angelillo, I. F. (2007). Preventable hospitalization and access to primary health care in an area of Southern Italy. BMC Health Serv Res, 7, 134. doi:10.1186/1472-6963-7-134

Rosenbaum, S., Paradise, J., Markus, A. R., Sharac, J., Tran, C., Reynolds, D., \& Shin, P. (2017). Community health centers: recent growth and the role of the ACA.

Rowley, W. R., Bezold, C., Arikan, Y., Byrne, E., \& Krohe, S. (2017). Diabetes 2030: Insights from Yesterday, Today, and Future Trends. Popul Health Manag, 20(1), 6-12. doi:10.1089/pop.2015.0181

Rust, G., Baltrus, P., Ye, J., Daniels, E., Quarshie, A., Boumbulian, P., \& Strothers, H. J. T. J. o. R. H. (2009). Presence of a community health center and uninsured emergency department visit rates in rural counties. 25(1), 8-16.

Smetana, G. W., Nathan, D. M., Dugdale, D. C., \& Burns, R. B. J. A. o. I. M. (2019). To What Target Hemoglobin A1c Level Would You Treat This Patient With Type 2 Diabetes?: Grand Rounds Discussion From Beth Israel Deaconess Medical Center. 171(7), 505-513.

Smith, L. I. (2002). A tutorial on principal components analysis. Retrieved from

Sraders, A. (2018). What Is the 2018 Federal Poverty Level in the U.S.? Retrieved from https://www.thestreet.com/personal-finance/what-is-the-federal-poverty-level$\underline{14690998}$

State Health Facts. (2017). Distribution of the Total Population by Federal Poverty Level (above and below 200\% FPL). Retrieved from https:/www.kff.org/other/stateindicator/population-up-to-200$\underline{\mathrm{fpl}} /$ ? currentTimeframe $=0 \&$ selectedDistributions $=$ under200percent\&sortModel $=\% 7 \mathrm{~B} \% 22$ colId $\% 22: \% 22$ Location $\% 22, \% 22$ sort $\% 22: \% 22$ $\operatorname{asc} \% 22 \% 7 \mathrm{D}$

Stevens, C. D., Schriger, D. L., Raffetto, B., Davis, A. C., Zingmond, D., \& Roby, D. H. (2014). Geographic clustering of diabetic lower-extremity amputations in lowincome regions of California. Health Aff (Millwood), 33(8), 1383-1390. doi:10.1377/hlthaff.2014.0148

Stockbridge, E. L., Chhetri, S., Polcar, L. E., Loethen, A. D., \& Carney, C. P. (2019). Behavioral health conditions and potentially preventable diabetes-related hospitalizations in the United States: Findings from a national sample of commercial claims data. PLoS One, 14(2), e0212955. doi:10.1371/journal.pone.0212955

Taber, J. M., Leyva, B., \& Persoskie, A. J. J. o. g. i. m. (2015). Why do people avoid medical care? A qualitative study using national data. 30(3), 290-297. 
Tampah-Naah, A. M., Osman, A., \& Kumi-Kyereme, A. (2019). Geospatial analysis of childhood morbidity in Ghana. PLoS One, 14(8), e0221324. doi:10.1371/journal.pone.0221324

Thom, D. H., \& Bodenheimer, T. (2017). Approaches to Integrated Diabetes Care: United States: San Francisco. In Integrated Diabetes Care (pp. 31-50): Springer.

Van Loenen, T., Faber, M. J., Westert, G. P., \& Van den Berg, M. J. (2016). The impact of primary care organization on avoidable hospital admissions for diabetes in 23 countries. Scand J Prim Health Care, 34(1), 5-12. doi:10.3109/02813432.2015.1132883

Veru-Lesmes, F., Rho, A., Joober, R., Iyer, S., \& Malla, A. (2019). Socioeconomic deprivation and blood lipids in first-episode psychosis patients with minimal antipsychotic exposure: Implications for cardiovascular risk. Schizophr Res. doi:10.1016/j.schres.2019.12.019

Wager, K. A., Lee, F. W., \& Glaser, J. P. (2017). Health care information systems: a practical approach for health care management: John Wiley \& Sons.

Wen, H., Johnston, K. J., Allen, L., \& Waters, T. M. (2019). Medicaid Expansion Associated With Reductions In Preventable Hospitalizations. Health Aff (Millwood), 38(11), 1845-1849. doi:10.1377/hlthaff.2019.00483

Yaqoob, M., Wang, J., Sweeney, A. T., Wells, C., Rego, V., \& Jaber, B. L. (2018). Trends in Avoidable Hospitalizations for Diabetes: Experience of a Large Clinically Integrated Health Care System. J Healthc Qual. doi:10.1097/JHQ.0000000000000145

Zou, B., Peng, F., Wan, N., Mamady, K., \& Wilson, G. J. (2014). Spatial cluster detection of air pollution exposure inequities across the United States. PLoS One, 9(3), e91917. doi:10.1371/journal.pone.0091917 


\title{
CURRICULUM VITAE
}

\author{
Turky J Arbaein, PhD, MHA, BSLM \\ School of Public Health and Information Sciences \\ University of Louisville \\ Phone: 678-674-7478 \\ tiarbaein@uqu.edu.sa
}

\section{$\underline{\text { EDUCATION }}$}

B.S. in Laboratory Medicine (2010)

College of Applied Medical Sciences, Umm Al-Qura University, Saudi Arabia

\section{M.S. Health Administration (2015)}

College of Health, Clayton State University, Atlanta, Georgia

Ph.D. Public Health, Health Management (2020)

School of Public Health \& Information Sciences University of Louisville, Kentucky

\section{PROFESSIONAL EXPERIENCE}

\section{Teaching Assistant (2011 - 2012)}

Department of Health Policy and Management,

Public Health College at Umm Al-Qura University, Saudi Arabia.

Graduate Research Assistant (2015 - 2017)

University of Louisville, School of Public Health \& Information Sciences Commonwealth Institute of Kentucky (CIK) 


\section{PROJECTS}

\section{Oral Presentations}

Arbaien, T., Paige, Carla. (Jan, 2015). Shall we follow, or find our path to a healthier future .

Oral Presentation presented at: MBAA International Conference - March 25-27, 2015 in Chicago.

\section{Poster Presentations}

Arbaein, T; Ahmed, M. "Quality of Life Among Syrian Refugees in Louisville Kentucky: A Community-Based Participatory Research Study Examining the Challenges and Difficulties

Encountered by the Syrian Refugees During Their Settlement in Louisville Kentucky". Poster presented at the 69th KPHA Annual Meeting April 12, 2017, Owensboro, KY, USA.

Accepted to present at the American Public Health Association (APHA) 2017 Annual Meeting Nov. $5^{\text {th }}$ in Atlanta, Georgia, United States. 